\title{
Methodology for Determining Criteria for Storing Spent Fuel in Air
}

\section{November 1986}

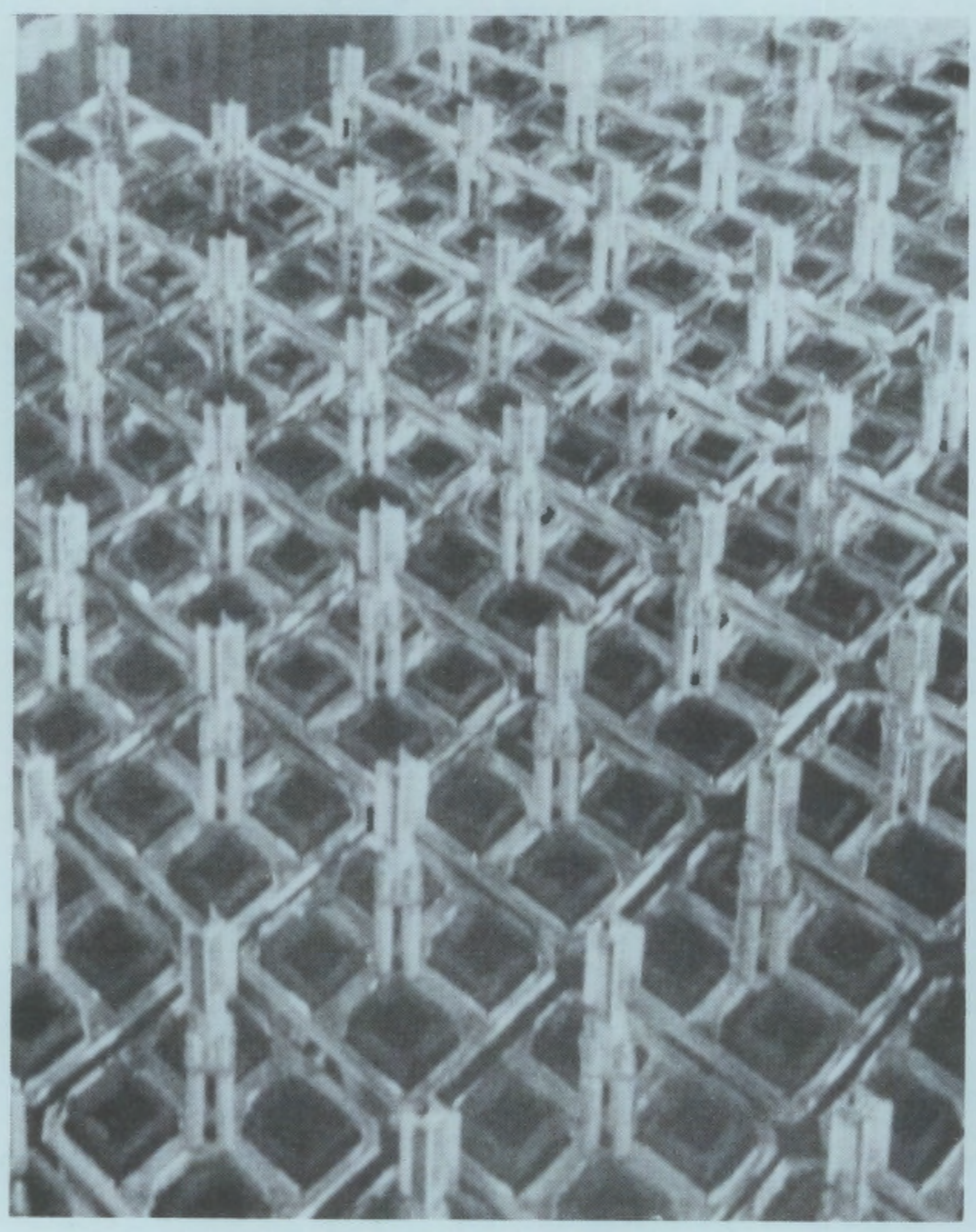

Prepared for the U.S. Department of Energy under Contract DE-AC06-76RLO 1830

Pacific Northwest Laboratory Operated for the U.S. Department of Energy by Battelle Memorial Institute 


\title{
DISCLAIMER
}

This report was prepared as an account of work sponsored by an agency of the United States Government. Neither the United States Government nor any agency thereof, nor Battelle Memorial Institute, nor any of their employees, makes any warranty, expressed or implied, or assumes any legal liability or responsibility for the accuracy, completeness, or usefulness of any information, apparatus, product, or process disclosed, or represents that its use would not infringe privately owned rights. Reference herein to any specific commercial product, process, or service by trade name, trademark, manufacturer, or otherwise, does not necessarily constitute or imply its endorsement, recommendation, or favoring by the United States Government of any agency thereof, or Battelle Memorial Institute. The views and opinions of authors expressed herein do not necessarly state or reflect those of the United States Government or any agency thereof, or Battelie Memorial Institute.

\author{
PACIFIC NORTHWEST LABORATORY \\ operated by \\ BATTELLE \\ for the \\ UNITED STATES DEPARTMENT OF ENERGY \\ under Contract DE-AC06-76RLO 1830
}

\begin{tabular}{|c|c|}
\hline \multirow{2}{*}{\multicolumn{2}{|c|}{ Printed in the United States of America }} \\
\hline & \\
\hline \multicolumn{2}{|c|}{$\begin{array}{l}\text { Available from } \\
\text { National Technical Information Service }\end{array}$} \\
\hline \multicolumn{2}{|c|}{$\begin{array}{l}\text { National Technical Information Service } \\
\text { United States Department of Commerce }\end{array}$} \\
\hline \multicolumn{2}{|c|}{5285 Port Royal Road } \\
\hline \multicolumn{2}{|c|}{ Springfield, Virginia 22161} \\
\hline \multirow{2}{*}{\multicolumn{2}{|c|}{$\begin{array}{l}\text { NTIS Price Codes } \\
\text { Microfiche A01 }\end{array}$}} \\
\hline & \\
\hline \multicolumn{2}{|c|}{ Printed Copy } \\
\hline & Price \\
\hline Pages & \\
\hline $001-025$ & $\mathrm{~A} 02$ \\
\hline $026-050$ & $\mathrm{~A} 03$ \\
\hline $051-075$ & A04 \\
\hline $076-100$ & A05 \\
\hline $101-125$ & A06 \\
\hline $126-150$ & $\mathbf{A} 07$ \\
\hline $151-175$ & $A 0 B$ \\
\hline $176-200$ & A09 \\
\hline $201-225$ & A010 \\
\hline $226-250$ & A011 \\
\hline $251-275$ & A012 \\
\hline $276-300$ & A013 \\
\hline
\end{tabular}



C. R. Reid
E. R. Gilbert

November 1986

Prepared for the U.S. Department of Energy under Contract DE-AC06-76RLO 1830

Pacific Northwest Laboratory Richland, Washington 99352 


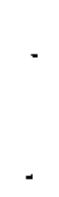


SUMMARY

Dry storage in an air atmosphere is a method being considered for spent light water reactor (LWR) fuel as an alternative to storage in an inert gas environment. However, methods to predict fuel integrity based on oxidation behavior of the fuel first must be evaluated. In the past, tests conducted to determine spent fuel oxidation behavior mostly have been performed under shortterm, constant temperature conditions. During storage, however, temperatures change due to the decay heat behavior of spent fuel and fluctuations in the ambient temperature. Modeling is needed to predict when LWR spent fuel oxidation reaches an unacceptable stage, such as powder formation, during dry storage in an air atmosphere. These predictions are necessary to determine when monitoring for inert atmosphere maintenance can be terminated and to assess the effect of abnormal events. The methods by which these predictions are made need to be verified by performing specific nonconstant temperature tests and should be modified as indicated by the results of the tests.

The linear cumulative damage method has been proposed as a technique for defining storage criteria. Analysis of limited nonconstant temperature data on nonirradiated fuel samples indicates that this approach yields conservative results for a strictly decreasing-temperature history. On the other hand, the description of damage accumulation in terms of remaining life concepts provides a more general framework for making predictions of failure. Accordingly, a methodology for adapting remaining life concepts to $\mathrm{NO}_{2}$ oxidation has been deveioped at Pacific Northwest Laboratory.

Both the linear cumulative damage and the remaining life methods were used to predict oxidation results for spent fuel in which the temperature was decreased with time to simulate the temperature history in a dry storage cask. The numerical input to the methods was based on oxidation data generated with nonirradiated $\mathrm{UO}_{2}$ pellets. The calculated maximum allowable storage temperatures are strongly dependent on the temperature-time profile and emphasize the conservatism inherent in the linear cumulative damage model. Additional nonconstant temperature data for spent fuel are needed to hoth validate the proposed methods and to predict temperatures applicable to actual spent fuel storage. 


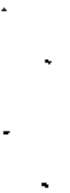




\section{ACKNOWLEDGMENTS}

The work discussed in this report was supported by the U.S. Department of Energy, Office of Civilian Radioactive Waste Management through the Commercial Spent Fuel Management Division of the Richland Operations office. The project was managed through the PNL Comnercial Spent Fuel Management Office.

The comments of Dr. R. E. Einziger (Hanford Engineering Deveiopment Laboratory), J. A. Nevshemal (Chairman ANS-57.9 Dry Storage Installation Design Standard), and Professor G. E. Lucas (University of California, Santa Barbara) on an early draft are gratefully acknowledged. A special note of appreciation is extended to Professor D. R. 01 ander (University of California, Berkeley) for his very substantial comments and helpful suggestions on the methodology and organization. 

CONTENTS

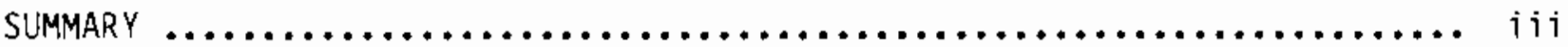

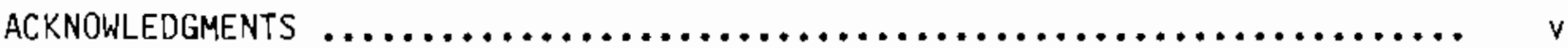

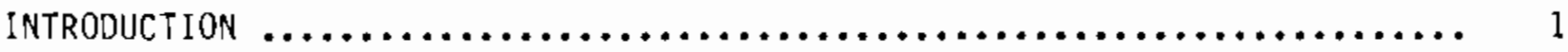

CONCLUSIONS $\ldots \ldots \ldots \ldots \ldots \ldots \ldots \ldots \ldots \ldots \ldots \ldots \ldots \ldots \ldots \ldots \ldots \ldots \ldots \ldots \ldots \ldots \ldots \ldots$

FUEL OXIOATION ANO DEGRADATION $\ldots \ldots \ldots \ldots \ldots \ldots \ldots \ldots \ldots \ldots \ldots \ldots \ldots \ldots \ldots$

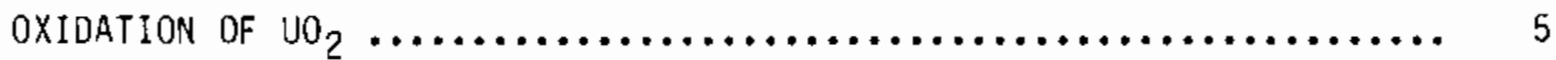

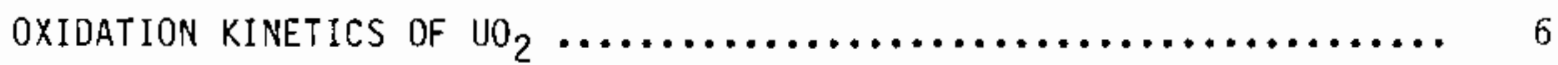

DEFINITION OF FAILURE $\ldots \ldots \ldots \ldots \ldots \ldots \ldots \ldots \ldots \ldots \ldots \ldots \ldots \ldots \ldots \ldots$

METHODOLOGY FOR PREDICTING FAILURE AND NONCONSTANT TEMPERATURE DATA $\ldots . . . \quad 11$

METHOOS FOR PREDICTING TIME TO FAILURE $\ldots \ldots \ldots \ldots \ldots \ldots \ldots \ldots \ldots \ldots \ldots$

Linear Cumulative Damage Method ...................... 11

Remaining Life Method ............................. 12

PNL STEP TEMPERATURE CHANGE TESTS $\ldots \ldots \ldots \ldots \ldots \ldots \ldots \ldots \ldots \ldots \ldots \ldots \ldots \ldots$

INTERPRETATION OF NONCONSTANT TEMPERATURE DATA $\ldots \ldots \ldots \ldots \ldots \ldots \ldots \ldots \ldots$

METHOO FOR CALCULATING MAXIMUM ALLOWABLE TEMPERATURES $\ldots \ldots \ldots \ldots \ldots \ldots$

uSE OF THE LINEAR Cumulative Damage METHOO $\ldots \ldots \ldots \ldots \ldots \ldots \ldots \ldots \ldots \ldots$

USE OF THE REMAINING LIFE METHOD $\ldots \ldots \ldots \ldots \ldots \ldots \ldots \ldots \ldots \ldots \ldots \ldots \ldots \ldots$

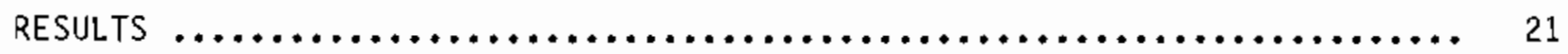

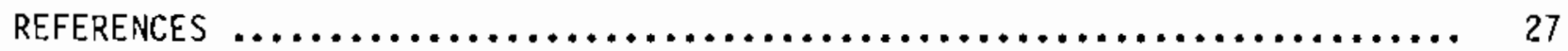

APPENDIX - DEVELOPMENT OF METHODS FOR OESCRIBING CUMULATIVE DAMAGE ...... A.I 

FIGURES

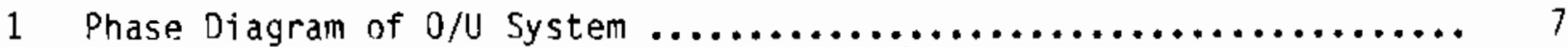

2 Remaining Life Data From Nonconstant Temperature Change Tests

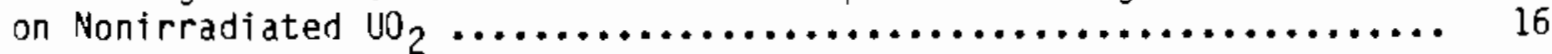

3 Estimates of Temperature History for BWR Spent Fuel

in the REA Cask $\ldots \ldots \ldots \ldots \ldots \ldots \ldots \ldots \ldots \ldots \ldots \ldots \ldots \ldots \ldots \ldots \ldots \ldots \ldots . \ldots \ldots$

A.l Illustration of the Method for Obtaining Remaining Life Curves

A.2 Remaining Life Curves When Linear Cumulative Damage is Operable

\section{TABLES}

1 Constant Temperature Tests on Nonirradiated $v_{2}$ Pellets $\ldots \ldots \ldots \ldots \ldots$

2 Step Temperature Change Tests on Nonirradiated $\mathrm{UO}_{2}$ Pellets ......... 15

3 Maximum Allowable Temperatures for Dry Storage Calculated

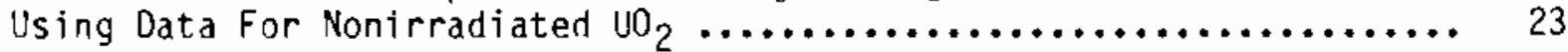

4 Maximum Allowable Temperatures for Dry Storage Calculated

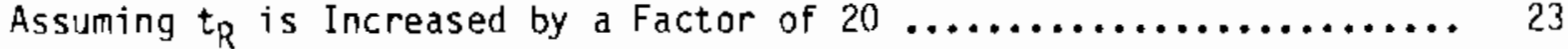

5 Effects of Changing Some of the Input Parameters in the Remaining Life Method 


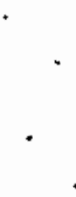


INTRODUCTION

Dry storage of spent light water reactor (LWR) fuel is becoming increasingly important because the present modes of storage are reaching their capacity. Through the Commercial Spent Fuel Management Program, the Department of Energy is assisting U.S. utilities to become licensed for dry storage at LWR reactor sites. Such storage would be necessary until the spent fuel is transported to a government-operated Monitored Retrievable Storage (MRS) facility or geologic repository in 1998. Dry storage involves placing the fuel into metal casks, silos, or vaults in the presence of a gaseous environment. If the environment is nonoxidizing, the fuel will not degrade appreciably for extended time periods even at relatively high temperatures (Johnson and Gilbert 1983a). An alternative method would be to store LWR fuel in an air atmosphere, which would provide increased flexibility and additional interim storage options. However, the possible consequences of exposing breached spent fuel rods to air must be determined.

While oxidation of the fuel cladding is not a primary concern (Peehs and Fleisch 1986, Johnson and Gilbert 1983b, Blackburn et al. 1978), oxidation of $\mathrm{UO}_{2}$ to compounds with higher oxygen/uranium $(0 / \mathrm{U})$ ratios can result in products with a lower density than the original material. The resulting expansion of the fuel produces stresses that can cause the cladding to breach and oxidized fuel to be released as respirable particles.

In the past, tests to determine oxidation behavior of spent fuel have been performed under constant (steady state) temperature conditions for periods of time seldom exceeding 3 years. Modeling the stability of fuel forms for extended periods of storage requires extrapolations significantly beyond the existing data base with regard to the constant temperature conditions for which the data were generated and the test durations. These extrapolations require assumptions about the continuity of the oxidation phenomena from the relatively short test periods to several decades.

Damage accumulation methods provide an approach by which failure of spent fuel, defined in this report as the time to powder formation, can be predicted 
under nonconstant (nonsteady state) temperature conditions. These methods provide a means for estimating parameters such as maximum allowable storage temperatures.

Previous calculations that incorporate the variable temperature history associated with dry storage have relied exclusively upon the 1 inear cumulative damage method (Gilbert et a1. 1983; White, Gilbert, and Johnson 1983; Wheeler 1983; Einziger and Strain 1986). Analysis of limited nonconstant (nonsteady state) temperature test data obtained at Pacific Northwest Laboratory (PNL) (a) suggest that such an approach may be overconservative for declining temperature with time. A more general method for estimating dry storage criteria under nonconstant temperature conditions, based on remaining life concepts (Woodforc. 1979), was developed at PNL and is presented in this report. The linear cumulative damage method is shown to be a special case of the remaining life method. Sample calculations using both methods are made, and the results are compared.

An approach for implementing the remaining life method is put forth in this report, and calculations of the maximum allowable storage temperatures are made. Qualitative temperature-time histories were simulated using the ORIGEN-2 code (Croff 1980) for decay heat behavior in conjunction with the thermal properties of a typical storage system. The maximum temperatures so calculated are strongly dependent upon the shape of the temperature curve and, to a slightly lesser extent, other factors such as fuel burnup. Additional nonconstant temperature data are needed both to confirm the applicability of the method to spent fuel oxidation and to validate the predictive capability of the method. The appendix explains the development of methods for describing damage accumulation.

(a) Operated for the U.S. Department of Energy by Battelle Memorial Institute under Contract DE-AC06-76RL.0 1830. 
CONCLUSIONS

Several conclusions can be made as a result of the work discussed in this report. The conclusions are qualitative in nature because the required data for spent fuel are lacking. The conclusions can be stated as follows:

1. Damage accumulation methods can be used to predict storage criteria. However, additional data are needed to build confidence in the methods and in the actual numerical parameters required by the methods.

2. Analysis of limited nonconstant temperature data indicated that the linear cumulative damage method yields conservative estimates of time to failure for decreasing-temperature histories. The simplicity of its application and its conservatism makes the linear cumulative damage method attractive for determining storage criteria.

3. A general operational method for predicting fuel integrity based on the concept of remaining life has been developed but will be of limited use until more nonconstant temperature data are available. Uncertainties in some of the assumptions required for its implementation should be addressed.

4. Accurate predictions of maximum allowable temperature for spent fuel storage under oxidizing conditions cannot be made because sufficient data are not available. The sensitivity of this temperature to the actual storage temperature profiles, and to a lesser extent the burnup of the fuel, suggests that such calculations may have to be made on a case-by-case basis. A generic maximum allowable temperature cannot be defined, except for worst-case conditions that would be unnecessarily penalizing for most spent fuels because of the sensitivity of such a temperature to the above parameters. 


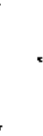


FUEL OXIDATIUN AND DEGRADATION

Because a small percentage of spent fuel rods contain cladding defects (Bailey et al. 1984), air will have access to the $\mathrm{UO}_{2}$ fuel if an inert atmosphere is not maintained within the storage system. Oxidation of fuel in an unlimited air atmosphere may result in the formation of oxides with increasing $0 / U$ ratios. The primary oxidation products found in oxidized fuel specimens are $U_{4} 0_{9}, U_{3} O_{7}, U_{3} 0_{8}$ and $U_{3}$. Since $U 0_{2}$ has a density of $10.97 \mathrm{~g} / \mathrm{cm}^{3}$ and $U_{3} U_{7}$ has a density of $11.4 \mathrm{~g} / \mathrm{cm}^{3}$, the formation of $U_{3} 0_{7}$ results in a slight molar volume decrease of about $0.03 \%$. A similar situation results if $\mathrm{UO}_{2}$ oxidizes to $\mathrm{U}_{4} \mathrm{O}_{9}$

The formation of $\mathrm{U}_{3} \mathrm{O}_{7}$ or $\mathrm{U}_{4} \mathrm{O}_{9}$ does not jeopardize the integrity of the fuel cladding; however, the formation of $U_{3} \mathrm{O}_{8}$ with a density of $8.35 \mathrm{~g} / \mathrm{cm}^{3}$ represents a molar volume increase of about $36 \%$. $\mathrm{UO}_{3}$ also has a lower density than $\mathrm{UO}_{2}\left(7.9 \mathrm{~g} / \mathrm{cm}^{3}\right)$, and its formation also increases the volume of the fuel. Such a volumetric expansion causes the fuel to transform into a dispersible powder and leads to cladding strain and rupture if enough $U_{3} O_{8}$ and/or $\cup 0_{3}$ is formed. The contamination potential may therefore be enhanced by: 1) oxidation of the fuel along the grain boundaries, which could release fission gas; 2) fallout of fuel particulate from the ruptured cladding; and 3) spallation of the cladding crud as a result of stresses imposed on the cladding 101 sen 1985b).

The extended integrity of the spent fuel is determined primarily by the oxidation rate and the time to degrade the cladding by formation of $\mathrm{U}_{3} \mathrm{O}_{8}$. The following sections briefly discuss the oxidation of $\mathrm{VO}_{2}$ and factors influencing the rate. A definition for failure is also given, which is used in the methods for predicting fuel integrity.

OXIDATION OF U0

Numerous studies have attempted to define the process of oxidation. In the temperature range of $-183^{\circ} \mathrm{C}$ to $-130^{\circ} \mathrm{C}$, oxygen is chemisorbed onto the uranium dioxide surface (Roberts 1954). Between $-130^{\circ} \mathrm{C}$ and $50^{\circ} \mathrm{C}$, surface oxidation apparently occurs, forming a product several layers deep into the 
dioxide surface; while above $60^{\circ} \mathrm{C}$, matrix oxidation can occur (Anderson, Roberts, and Harper 1954). Because oxidation of the fuel above $150^{\circ} \mathrm{C}$ proceeds initially along fuel cracks and grain boundaries (191sen 1985b; Thomas, McCarthy, and Gilbert 1986; Einziger and Woodley 1985; White, Gilbert, and Johnson 1983; Wasywich 1984), oxidation can be found within a bulk sample before significant volume transformation of the material has occurred. Once the accessible surfaces bave oxidized, the matrix of individual grains begins to oxidize. The oxidation rate decreases to the rate controlled by oxidation of the single grains.

The process of oxidation is thought to be two steps in which the $\mathrm{UO}_{2}$ first oxidizes to $\mathrm{U}_{4} \mathrm{O}_{9}$ or $\mathrm{U}_{3} \mathrm{O}_{7}$, then subsequent oxidation produces $\mathrm{U}_{3} \mathrm{O}_{8}$ (Aronson 1957). Both of these transformations are thermodynamically possible as indicated by the negative free energies for the reactions of these compounds with oxygen even at room temperature (Gilbert, Knox, and White 1985). However, the possibility of a reaction does not necessarily indicate that it actually will proceed nor does it indicate the rate of reaction. In Figure 1 (Naito and Kamegashira 1976), $\mathrm{U}_{3} \mathrm{O}_{8}$ and $\mathrm{UO}_{3}$ appear as the stable products of $\mathrm{UO}_{2}$ oxidation at the temperatures and oxygen pressures of interest. A sample of $\mathrm{UO}_{2}$ maintained at room temperature for about 16 years showed the presence of only $\mathrm{UO}_{2}$ and hydrated $\mathrm{UO}_{3}$ (Wadsten 1977). Thus, the presence of $\mathrm{U}_{3} \mathrm{O}_{7}$ in oxidizing fuel suggests that it merely may be a metastable intermediate product. The fact that $\mathrm{U}_{3} \mathrm{O}_{8}$ has been found in fuel oxidation experiments on $\mathrm{UO}_{2}$ at $230^{\circ} \mathrm{C}(0 \mathrm{Tsen}$ $1985 \mathrm{~b}$ ) and at $200^{\circ} \mathrm{C}$ (Simpson and Wood 1984) substantiates the above observations.

\section{OXIDATION KINETICS OF $\mathrm{UO}_{2}$}

Many attempts have been made to quantify the reaction kinetics of $\mathrm{UO}_{2}$ oxidation. Experimentally, weight gain is the most. often used parameter for describing the process. The variability in the data so obtained indicates that many factors influence oxidation of spent fuel. For example, irradiation (burnup) influences the rate of weight gain and time to powder $\left(\mathrm{U}_{3} \mathrm{O}_{\mathrm{y}}\right)$ formation. Nonirradiated fuel gains weight at a slower initial rate than irradiated fuel (Hastings et al. 1984, Hastings et al. 1983, Novak and Hastings 1983), but. 


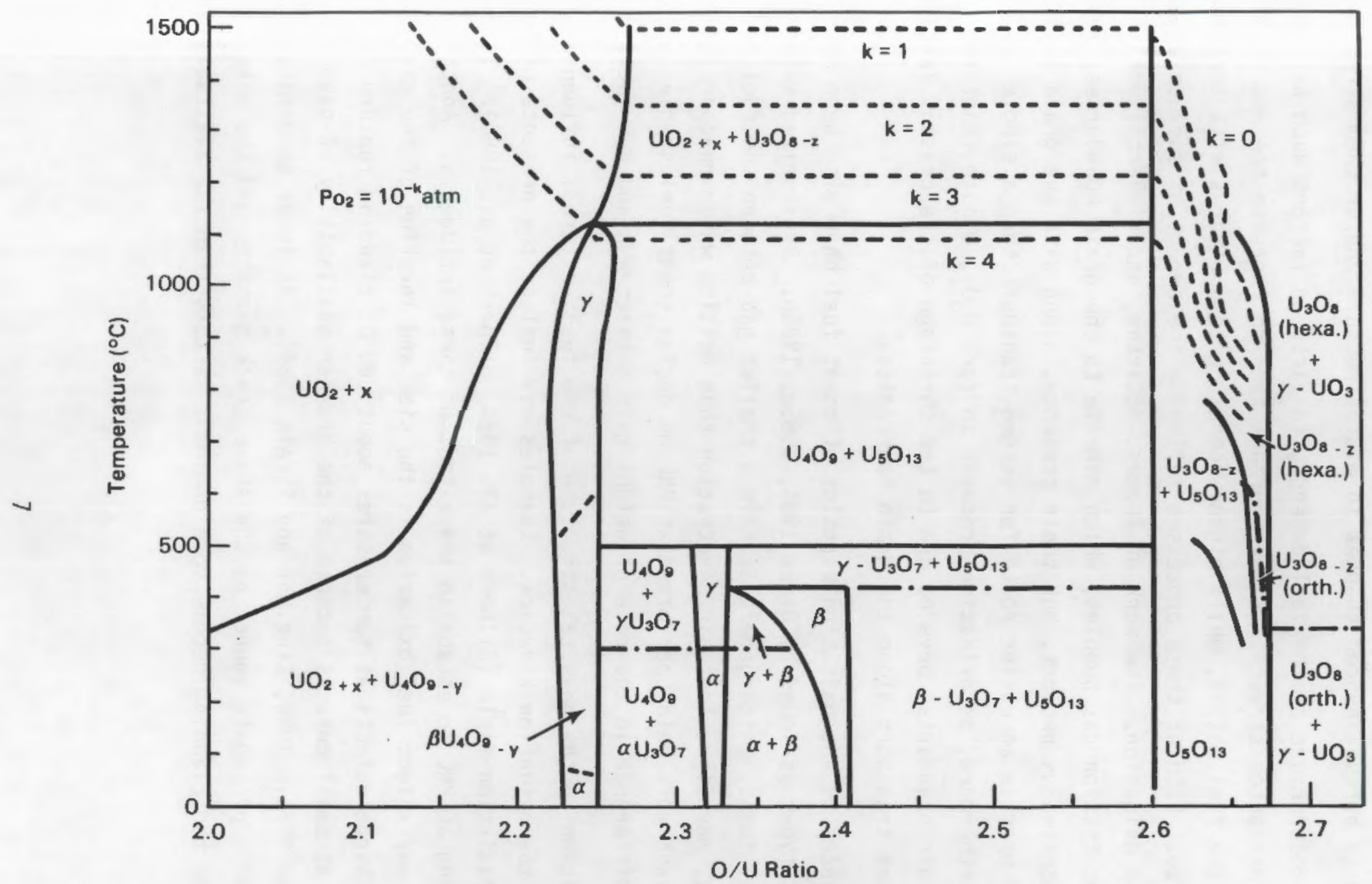

FIGURE 1. Phase Diagram of $0 / U$ System (Naito and Kamegashira 1976) 
has a shorter time to powder formation (Gilbert et al. 1984). Because irradiation does not appear to change the fundamental process of oxidation (Harrison, Padgett, and Scott 1967), the observed differences in oxidation rates are probably due to burnup-induced changes in microstructure and/or chemistry.

The microstructure of the fuel depends, in part, on factors such as fabrication and in-reactor service. Higher burnups tend to increase the amount of porosity in the fuel matrix, while higher operating temperatures will increase the grain size. Both of these processes influence the amount of surface area available for oxidation. The work of Thomas, McCarthy, and Gilbert (1986) suggests that fission gas bubbles, which migrate to the grain boundaries, may not form a continuous network, but their presence, along with the grain boundaries, would provide an easier route for oxygen transport than a single crystal. Furthermore, as oxidation proceeds to form $U_{3} 0_{7}$, minute fractures along the grain boundaries develop due to the shrinkage of the crystal lattice, which enhances transport along the grain boundaries.

Differences in the oxidation kinetics of spent fuel have also been noted between fuel types as found by 01 sen 1984, 1985a, 1985b. Pressurized water reactor (PWR) fuels, which generally have a smaller gap between the fuel and the cladding, may allow less air penetration than boiling water reactor (BWR) fuels. Present work being performed at PNL on declad spent fuel samples also suggests a difference in the rate of weight gain between PWR and BWR fuel.

In addition to the physical structure of the fuel, external influences may also impact the oxidation kinetics. Examples may include the presence of moisture and a radiation field (Gilbert et al. 1984, Gilbert et al. 1986). Tests are continuing at PNL to establish the extent of these influences. Another factor that may affect fuel oxidation is the size and location of the cladding defect. In large defects at temperatures about $300^{\circ} \mathrm{C}$, cladding rupture occurs sooner than at small defects because of the greater availability of oxygen (Einziger and Strain 1986, Einziger and Strain 1984). At lower temperatures, smaller defects propagate sooner as the sharp crack geometry and the material properties of the cladding become more dominant factors than the availability 
of oxygen. The location of the defect may be near a homogeneous region of the fuel, which would limit oxygen ingress over that of a defect near a fractured region of the fuel.

Various physically based models have been proposed to describe the reaction kinetics of $\mathrm{UO}_{2}$. Models such as Johnson and Mehl's (1939) for the nucleation and growth of $\mathrm{U}_{3} \mathrm{O}_{8}$, as well as various forms of reaction rates depending on surface areas and diffusion phenomena (Aronson, Roof, and Belle 1957;

Einziger and Woodley 1985), have met with limited success in certain instances. However, an encompassing theory has not been presented that accounts for all the data. The difficulty appears to be related to the wide variations in microstructure and chemistry as discussed above. Additionally, the simultaneous formation of $\mathrm{U}_{3} \mathrm{O}_{7}$ and $\mathrm{U}_{3} \mathrm{O}_{8}$ may further complicate the process. Because quantification of all the pertinent variables is unlikely, conservative estimates of reaction rates will have to be made. Factors such as burnup and microstructure can be included as the data become available.

DEFINITION OF FAILURE

A definition of failure is required by methods for predicting fuel integrity, and this definition should reflect some measurable item. One possibility is the time for declad fuel to oxidize to the extent where powder formation occurs. Another possibility would be to define failure as the time required for some specified cladding strain or time for rupture of the cladding to occur. Novak and Hastings (1983) noted that in the case of CANDU fuel, no sheath splitting occurred at strains Iess than $2 \%$. A conservative cladding creep strain criterion of $1 \%$ is used in the Federal Republic of Germany (Peehs and Fleisch 1986). From these examples, it may therefore be possible to define faiture in terms of the integrity of the fuel cladding.

In this report, time to powder formation is taken as the definition of failure because this quantity represents a conservative estimate for failure of fuel in dry storage (Einziger and Strain 1986). Cladding integrity criteria for failure could have been used, but the data on time to powder formation are more complete. The use of a specific weight gain as a measure of failure 
presently does not appear to be a suitable definition of failure because a relationship between this value and time to powder formation or cladding rupture has not yet been established. 
METHODOLOGY FOR PREDICTING FAILURE AND NONCONSTANT TEMPERATURE DATA

Prediction of the time to failure requires a method for extrapolating oxidation data from constant and nonconstant temperature oxidation tests to the conditions likely to occur during dry storage of spent fuel. Two methods for predicting failure of spent fuel under oxidizing conditions are discussed in this section. Applicable data on fuel oxidation under nonconstant temperature conditions are extremely limited. The available nonconstant temperature data obtained at PNL are presented in this section and the applicability of the failure prediction methods are discussed in light of the limited data.

METHOOS FOR PREDICTING TIME TO FAILURE

Methods for predicting failure of oxidizing spent fuel must be capable of handling nonconstant temperature histories. Two general approaches to the problem are the statistical and the cumulative damage approaches. The statistical approach (Bogdanoff and Kozin 1985) requires a large data base, which is not available for fuel oxidation occurring as a result of nonconstant temperature histories. A wide variety of methods employ cumulative damage approaches (Hwang and Han 1986) and generally are tailored to particular phenomena. The linear cumulative damage nethod (the Palmgren-Miner rule) has been used previously to estimate time to failure and to predict maximum allowable storaye temperatures (Einziger and Strain 1986; Gi lbert et al. 1983; Wheeler 1983; White, Gilbert, and Johnson 1983). This method is briefly discussed here, and a more general failure prediction method that includes the Palmgren-Miner rule as a special case is presented. The appendix gives a more complete description of the development of these cumulative damage methods.

Linear Cumulative Damage Method

The linear cumulative damage method is an application of the PaimgrenMiner rule, which is based on the assumption that the amount of damage incurred during any time increment is equal to the ratio of the time increment to the amount of time required for failure at that temperature for a nonoxidized 
specimen. This method implies that the damage incurred during any tiine increment is independent of the exposure history. The following is the mathematical statement of the method.

$$
\int_{0}^{t} \frac{d \tau}{t_{R}(T(\tau))}=D
$$

where $t_{R}$ is the time to failure under constant temperature conditions and $D$ is the amount of damage accumulated. Failure occurs when 0 is equal to 1.

\section{Remaining Life Method}

A general method for predicting the failure of fuel by oxidation is based on the remaining life of the material (Woodford 1979) rather than the life used up, as in the Palmgren-Miner rule. The remaining life method contains the linear cumulative damage rule as a special case. It is based on the concept of remaining life curves. Remaining life curves are a family of curves, each of which defines a particular state of partial oxidation in the material. A given curve displays the remaining life of a partially oxidized specimen as a function of temperature, and the temperature history dictates which curve presentiy describes the oxidation state of the specimen. Fatilure is predicted by use of the following differential equation:

$$
\frac{d t}{d t}=-1+\frac{\partial t}{\partial T} \frac{d T}{d t}
$$

In the above, $t_{r}$ is the current remaining life, $T$ is the absolute temperature, and $t$ is time. Failure occurs when the remaining life $\left(t_{r}\right)$ becomes zero. The term $\partial t_{r} / \partial T$ incorporates the character of the remaining life curves and $d T / d t$ allows for nonconstant temperature histories. Thus, the history of the damage can be addressed in this method by use of the remaining life curves. The appendix contains a more complete description of the development of remaininy life curves and the derivation of the above differential equation. 
PNL STEP TEMPERATURE CHANGE TESTS

Step temperature change tests on nonirradiated fuel were performed at PNL by $G$. D. White. A complete description of the test procedure and materials can be found in White, Gilbert, and Johnson (1983). These tests, though limited, provide some data from which the applicability of failure prediction methods can be tested. Although the tests were performed on nonirradiated fuel, the results should be applicable in general to spent fuel oxidation even though oxidation rates will undoubtedly be different for spent fuel. Specific tests on spent fuel will be required to validate this contention.

Methods for predicting failure of $\mathrm{UO}_{2}$ fuel as a result of oxidation require data concerning the time to powder formation as a function of temperature for initially nonoxidized fuel. Data from constant temperature tests on nonirradiated $\mathrm{UO}_{2}$ pellets (presented in Table 1 ) represent results from specimens similar in both microstructure and time spent in air storage at ambient temperature (these data are a subset of the data used by white, Gilbert, and Johnson 1983). Despite this selection, variations in the density of the pellets may influence the data. Additional uncertainty in the data arises from the experimental method for determining the time when powder first

TABLE 1. Constant Temperature Tests on Nonirradiated $\mathrm{UO}_{2}$ Pellets

\begin{tabular}{|c|c|c|c|c|c|}
\hline I $\left({ }^{\circ} \mathrm{C}\right)$ & $\begin{array}{l}\text { Pellet } \\
\text { Number }\end{array}$ & $\begin{array}{l}\text { oTheor. } \\
\text { Density }\end{array}$ & $\begin{array}{l}\text { Pre-Powder } \\
\text { Exam (h) }\end{array}$ & $\begin{array}{l}\text { Post-Powder } \\
\text { Exam (h) }\end{array}$ & $\begin{array}{l}\text { Average Time }{ }^{(a)} \\
\text { To Powder (h) }\end{array}$ \\
\hline $\begin{array}{l}200 \\
200 \\
200 \\
200\end{array}$ & $\begin{array}{r}68 \\
69 \\
70 \\
B\end{array}$ & $\begin{array}{l}95.35 \\
95.26 \\
94.98 \\
96.53\end{array}$ & $\begin{array}{l}2808 \\
2141 \\
2261 \\
2546\end{array}$ & $\begin{array}{l}3800 \\
2261 \\
2333 \\
2738\end{array}$ & $\begin{array}{l}3304 \\
2201 \\
2297 \\
2642\end{array}$ \\
\hline $\begin{array}{l}215 \\
215 \\
215\end{array}$ & $\begin{array}{l}1 \\
2 \\
3\end{array}$ & $\begin{array}{l}95.66 \\
95.63 \\
96.06\end{array}$ & $\begin{array}{r}1146 \\
982 \\
982\end{array}$ & $\begin{array}{l}1216 \\
1052 \\
1052\end{array}$ & $\begin{array}{l}1181 \\
1017 \\
1017\end{array}$ \\
\hline $\begin{array}{l}230 \\
230 \\
230\end{array}$ & $\begin{array}{l}34 \\
51 \\
52\end{array}$ & $\begin{array}{l}96.07 \\
96.44 \\
96.44\end{array}$ & $\begin{array}{l}285 \\
508 \\
508\end{array}$ & $\begin{array}{l}376 \\
578 \\
578\end{array}$ & $\begin{array}{l}331 \\
543 \\
543\end{array}$ \\
\hline
\end{tabular}

(a) Average of times for examinations prior to and following powder formation. 
forms. This time is bracketed by visual examinations before and after the powder forms. The means of the times for these two examinations were used in Table 1 to estimate the time powder started to form. These data suggest that the time to powder formation $\left(t_{R}\right)$ under constant temperature conditions can be given by an Arrhenius relation as follows:

$$
t_{R}=A_{0} \exp \left(Q_{0} / R T\right)
$$

where $A_{0}$ is a pre-exponential factor, $Q_{0}$ is an activation energy for the process, $R$ is the ideal gas constant, and $T$ is the absolute temperature. The calculated value for $A_{0}$ is $7.5 \cdot 10^{-10}$ hours and the value for $Q_{0}$ is $113.5 \pm$ $9.4 \mathrm{~kJ} / \mathrm{mole}$. The calculated activation energy is lower than the $121 \mathrm{~kJ} / \mathrm{mole}$ found by Simpson and Wood (1983) and the $147 \mathrm{~kJ} / \mathrm{mole}$ found by White, Gilbert, and Johnson (1983) for nonirradiated $\mathrm{vO}_{2}$.

Nonconstant temperature change tests were performed by subjecting fuel specimens to a single step temperature change. The procedure involved oxidizing a specimen at one temperature for a given period of time (less than the time to powder formation at that temperature) and then raising or lowering the temperature. The specimen was then kept at the second temperature until powder formation was detected. Table 2 gives the results of these step temperature change tests. The results are tabulated in terms of remaining life to be consistent with the failure prediction method discussion below. In this table, $t_{r}$ is the remaining life at the given temperature and $a$ is $t_{r} / t_{R}$ at the specified temperature. The quantities $A$ and $Q$ were calculated by fitting an equation of the form of Equation 3 to the points in the column labeled $t_{r}$. As in Table 1 , the data were selected so that the specimens considered had similar microstructures and similar storage times at ambient temperature.

\section{INTERPRETATION OF NONCONSTANT TEMPERATURE DATA}

The applicability of a predictive equation for the time to powder formation can be determined from the nonconstant temperature data. The data from Tables 1 and 2 are plotted in Figure 2 where the axes are indicative of an Arrhenius-type temperature dependence in the oxidation behavior. The constant 
TABLE 2. Step Temperature Change Tests on Nonirradiated $\mathrm{UO}_{2}$ Pellets

\begin{tabular}{|c|c|c|c|c|c|c|c|c|}
\hline $\begin{array}{l}\text { Pellet } \\
\text { Number }\end{array}$ & $\begin{array}{l}\text { STheor. } \\
\text { Density }\end{array}$ & $\begin{array}{l}\text { Temp. } \\
\left({ }^{\circ} \mathrm{C}\right)\end{array}$ & $\begin{array}{l}\text { Time } \\
\text { at } \\
\text { Temp. } \\
\text { (h) }\end{array}$ & $\begin{array}{l}\text { Remain- } \\
\text { ing } \\
\text { Life, } \\
+\quad(h) \\
\end{array}$ & $\begin{array}{c}\text { Time to } \\
\text { Powder } \\
\text { Formation, } \\
t_{R}(\mathrm{~h}) \\
\end{array}$ & $\begin{array}{c}a \\
\left(t_{r} /+_{R}\right) \\
\end{array}$ & $\begin{array}{c}\text { A } \\
\text { (h) }\end{array}$ & $\begin{array}{c}Q \\
(\mathrm{~kJ} / \mathrm{mo} / \mathrm{e}) \\
\end{array}$ \\
\hline B13 & 95.99 & $\begin{array}{l}200 \\
230\end{array}$ & $\begin{array}{c}622 \\
224 / 290\end{array}$ & $\begin{array}{l}1946 \\
257\end{array}$ & $\begin{array}{r}2568 \\
459\end{array}$ & $\begin{array}{l}0.76 \\
0.56\end{array}$ & $3.53 \cdot 10^{-12}$ & 133.5 \\
\hline$B 22$ & 96.62 & $\begin{array}{l}200 \\
230\end{array}$ & $\begin{array}{c}987 \\
69 / 138\end{array}$ & ${ }_{104}^{1581}(a)$ & $\begin{array}{r}2568 \\
459\end{array}$ & $\begin{array}{l}0.62 \\
0.23\end{array}$ & $2.41 \cdot 10^{-17}$ & 179.4 \\
\hline A13 & 26.53 & $\begin{array}{l}230 \\
200\end{array}$ & $\begin{array}{c}85 \\
2116 / 2501\end{array}$ & 2309 (a) & $\begin{array}{r}459 \\
2568\end{array}$ & $\begin{array}{l}0.81 \\
0.90\end{array}$ & $1.28 \cdot 10^{-10}$ & 120.0 \\
\hline
\end{tabular}

(a) Remaining life after the temperature step change was taken as the mean between the time of the interim examination before powder was observed and the time of the interim examination after powder was observed. The two times are shown In the column labeled "ime at temperature."

temperature data are denoted by the curve labeled $t_{R}$. The lines with arrows represent remaining life curves generated from the step temperature changes. The arrows indicate the directions the temperature were changed.

As noted in the appendix, if the linear cumulative damage method were a valid approximation to the oxidation behavior, the remaining life curves would be parallel to the reference time to powder formation curve. Although the data are limited, the remaining life curves tend to be skewed with respect to the reference constant temperature curve. The skewness tends to increase as the oxidation progresses. Therefore, the linear cumulative damage method may not be the best for predicting the failure of spent $\mathrm{UO}_{2}$ fuel under conditions of changing temperatures. If the linear cumulative damage model were exact, the $\alpha$ 's in Table 2 would be the same at both ends of a given test, and the calculated activation energies ( $Q$ 's in Table 2) for the remaining life curves would be approximately the same as the value for $Q_{0}$ in Equation 3 . However, the data tend to indicate a decrease in the value of $\alpha$ with an increase in temperature and an increase in the apparent activation energy with an increase in damage (oxidation). 


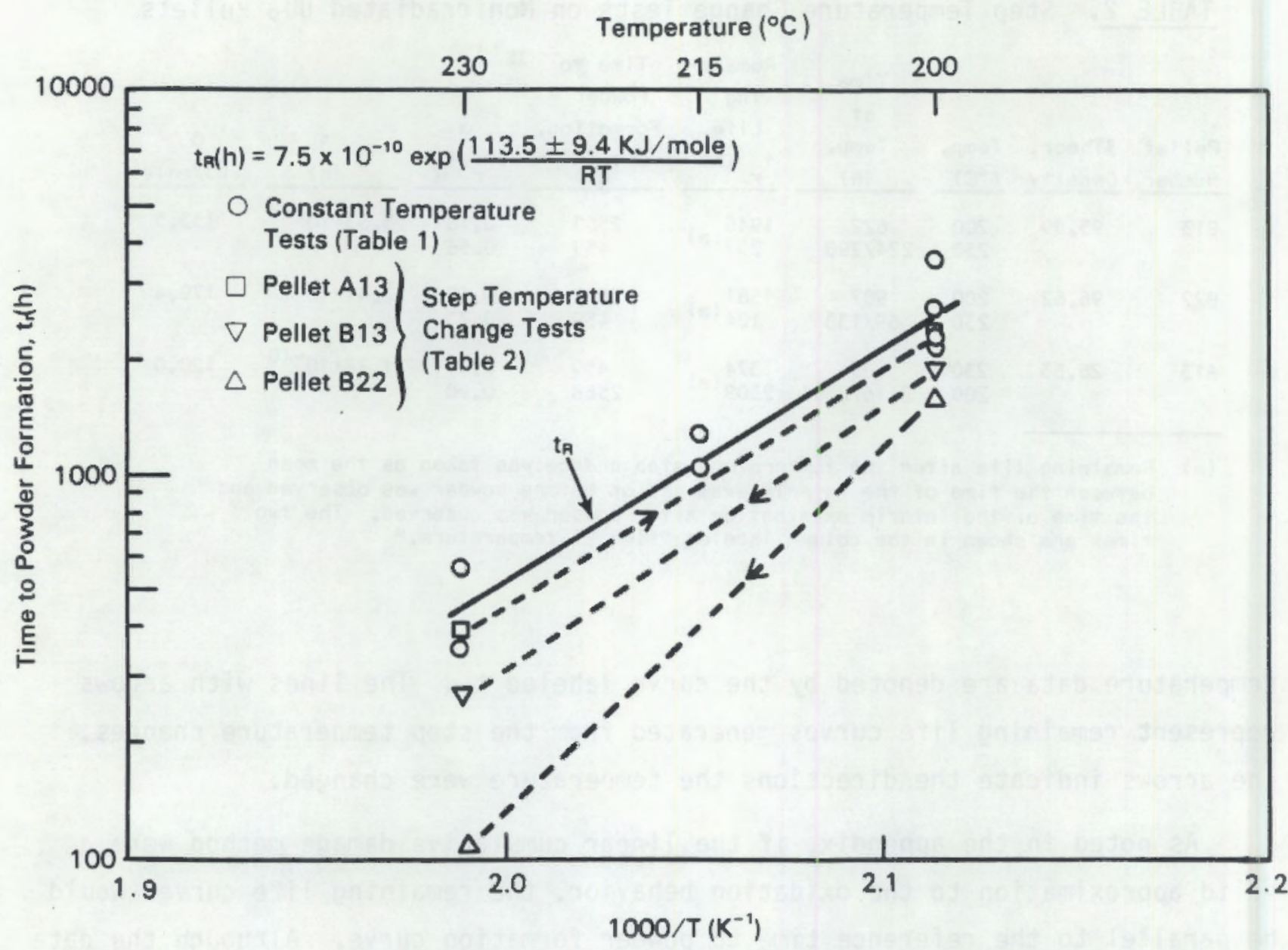

FIGURE 2. Remaining Life Data From Nonconstant Temperature Change Tests on Nonirradiated $\mathrm{UO}_{2}$

A qualitative explanation for the apparent change in activation energy as damage progresses can be given as follows. The measured activation energy for the time to powder formation at a constant temperature does not represent a single process, because the oxidation is a result of several concurrent processes. If the oxidation of spent fuel is assumed to be a two-step process, say $\mathrm{UO}_{2}$ to $\mathrm{U}_{3} \mathrm{O}_{7}$ and then $\mathrm{U}_{3} \mathrm{O}_{7}$ to $\mathrm{U}_{3} \mathrm{O}_{8}$, and the amount of damage is directly related to the amount of $\mathrm{U}_{3} \mathrm{O}_{8}$, then the rate of $\mathrm{U}_{3} \mathrm{O}_{8}$ formation and hence damage is dependent on the rates of each of the single steps (Moore 1962). As oxidation progresses, the relative contribution of each of the separate rates changes with time. Because the rates can be written as Arrhenius functions of temperature, the perceived activation energy for the total process will change 
with time as the oxidation proceeds. Although the oxidation of spent fuel is undoubtedly more complex than the above description, the same conclusions may sti11 app1y.

The skewness of the remaining life curves shown in Figure 2 indicates that the linear cumulative damage model would be conservative in a decreasingtemperature test but would be nonconservative in an increasing-temperature test. In other words, the linear cumulative damage model would predict powder formation before powder would actually form in a decreasing-temperature test but would not predict powder formation before its occurrence in an increasingtemperature test. Such a conclusion follows from the fact that the $a$ 's shown in Table 2 tend to increase with a decrease in temperature. These conclusions are consistent with observations of other damage phenomena that show a similar behavior relative to the linear cumulative damage model (Hwang and Han 1986).

If the curves shown in Figure 2 are extended to lower temperatures, they converge at a temperature near $175^{\circ} \mathrm{C}$. This convergence of the remaining life curves with the reference curve is consistent with creep rupture data presented by Woodford (1979). At present, however, no definitive explanation can be put forth to explain why the curves apparently converge at this temperature, and it would be inappropriate to infer that damaging oxidation ceases to occur at these lower temperatures. The oxidation mechanism may change in this region, and extrapolation of oxidation data from these temperature ranges to temperatures below $175^{\circ} \mathrm{C}$ should be done with caution (noted by Simpson and Wood 1983). If such a change were to occur near the temperature of convergence, the reference curve may show a change in activation energy, as it apparently does at temperatures above about $300^{\circ} \mathrm{C}$ (Boase and Vandergraff 1977). The phase transformation $a-U_{3} O_{7}+B-U_{3} \mathrm{O}_{8}$ above $180^{\circ} \mathrm{C}$ as reported by McCaldin and Somorjai (1975) may also be partly responsible for this conceptual difficulty.

The above discussion is based on a very limited data set from tests on nonirradiated fuel. Data variability may be, in part, responsible for some of the observed skewness in the remaining life curves. More step temperature change data are needed to validate the above conclusions. Factors such as fuel burnup and external radiation fields may also alter the specific numbers used in analysis. Such variations cannot be quantified at present, but current tests at PNL should provide some of the needed data. 
METHOD FOR CALCULATING MAXIMUM ALLOWABLE TEMPERATURES

The linear cumulative damage method and the remaining life method can be used to estimate failure of spent fuel in storage. Both methods can include nonconstant temperatures, and maximum allowable storage temperatures can be estimated for a given temperature-time profile. The procedure for calculating such temperatures is presented in this section.

\section{USE OF THE LINEAR CUMULATIVE DAMAGE METHOD}

Using the linear cumulative damage method to calculate the maximum allowable temperatures is relatively straightforward. Equation 1 is integrated over the required life of the storage system beginning at the time at which air is assumed to have access to the fuel ( $t_{R}$ is given by Equation 3$)$. If $D$ is greater than or equal to 1 , the initial temperature for the storage interval is too high and a lower temperature (corresponding to a longer cooling period) is required. Repeating the calculation yields the maximum allowable temperature for the given temperature-time profile.

Because the integral in Equation 1 cannot necessarily be solved analytically, numerical methods will generally be required. Numerical methods for integration are relatively stable and efficient, which makes it easy to implement the calculations.

\section{USE OF THE REMAINING LIFE METHOD}

The remaining life equation is an operational description for predicting failure. A method for applying this equation to fuel oxidation is outlined below.

At temperatures above the apparent point of convergence of the remaining life curves, the differential equation for remaining life (Equation 2) can be put into an explicit form by assuming an Arrhenius nature for these curves. This form of the equation is:

$$
\frac{d t_{r}}{d t}=-\left(1+\frac{{ }^{t} r}{T^{2}} \cdot \frac{Q\left(t_{r}, t\right)}{R} \cdot \frac{d T}{d t}\right)
$$


where $Q\left(t_{r}, t\right)$ is the apparent activation energy for the remaining life curve at the current point on the remaining life plot. This quantity can be calculated from the present value of remaining life and the value of $t_{R}$ at the temperature of convergence of the remaining life curves. Standard numerical methods can be used to evaluate $t_{r}(t)$ subject to the initial condition that $t_{r}(t=0)=$ $t_{R}(T(t=0))$.

Because of the lack of oxidation data for temperatures below the point of convergence (approximately $175^{\circ} \mathrm{C}$ ), a method for implementing the model cannot be developed for these low temperatures. The convergence of the remaining life curves introduces a singularity in the differential equation and indicates that either no damaging oxidation would occur at lower temperatures or that the oxidation mechanism may change. Destructive oxidation cannot be dismissed, however, as indicated by the high volume compounds shown in figure 1 at low temperatures. In order to address this problem, linear cumulative damage is assumed to become operable beginning at a temperature of $200^{\circ} \mathrm{C}$. This temperature was chosen because it is the lower limit of available nonconstant temperature oxidation data. (Sample calculations indicated minimal sensitivity to the actual choice of this cutoff limit.) The value of $Q\left(t_{r}, t\right)$ at temperatures below this limit is taken to be $Q_{0}$ where $Q_{0}$ is the value used in Equation 3. Any errors incurred by such an assumption should be conservative because linear cumulative damage methods tend to be conservative for decreasing-temperature histories.

As in the linear cumulative damage method, numerical methods are required to calculate the maximum allowable temperatures. The solution of differential equations is, in general, less stable and less accurate than the solution of integral equations, and the inclusion of the approximations outlined in the previous paragraphs makes this method less efficient for calculating maximum allowable storage temperatures. 
RESULTS

In this section, maximum allowable temperatures for fuel storage are predicted. These predictions are based on a limited set of data for nonirradiated fuel and consequently cannot be applied directly to the case of spent fuel storage. The purpose of this section is to use the methodology outlined in the previous section and to compare the results of the linear cumulative damaye method with the results of the remaining life method. Qualitative conclusions concerning the storage of spent fuel are made based on these results. Actual calculations of the maximum allowable storage temperature for spent fuel must be based on the precise mode of storage and data generated for spent fuel in a radiation environment.

The outlined methods for predicting failure of stored fuel are applied to the temperature histories shown in Figure 3. These temperature histories were calculated using predicted decay heats (ORIGEN-2 calculations, Croff 1980) of fuels with various degrees of burnup. The resulting temperature profiles were calculated using simple heat transfer correlations (Kreith and Black 1980) and data from temperature measurements of BWR spent fuel in the Ridihalgh, Eggers and Associates (REA) cask (Mckinnon et al. 1986). This simple analysis can give only a qualitative estimate of the dry storage temperatures because the overall heat transfer coefficient from the fuel rods to the cask surface was assumed to be independent of the fuel temperature. More accurate temperature calculations would require a much more detailed analysis (see, for example, Cuta, Rector, and Creer 1984; Rector, Cuta, and Creer 1986; Creer 1984; Wheeler et al. 1986).

Maximum allowable storage temperatures for given temperature profiles are shown in Table 3. A 40-year lifetime of the fuel in storage was used to determine these values. The temperatures were calculated using PNL-generated data for nonirradiated fuel and are not intended to represent values applicable to spent fuel. Time to failure (powder formation), which varies with burnup, was not considered, although the temperature histories are based on fuels with differing degrees of burnup. The temperatures calculated using the remaining life method and those using the linear cumulative damage method are shown. As 


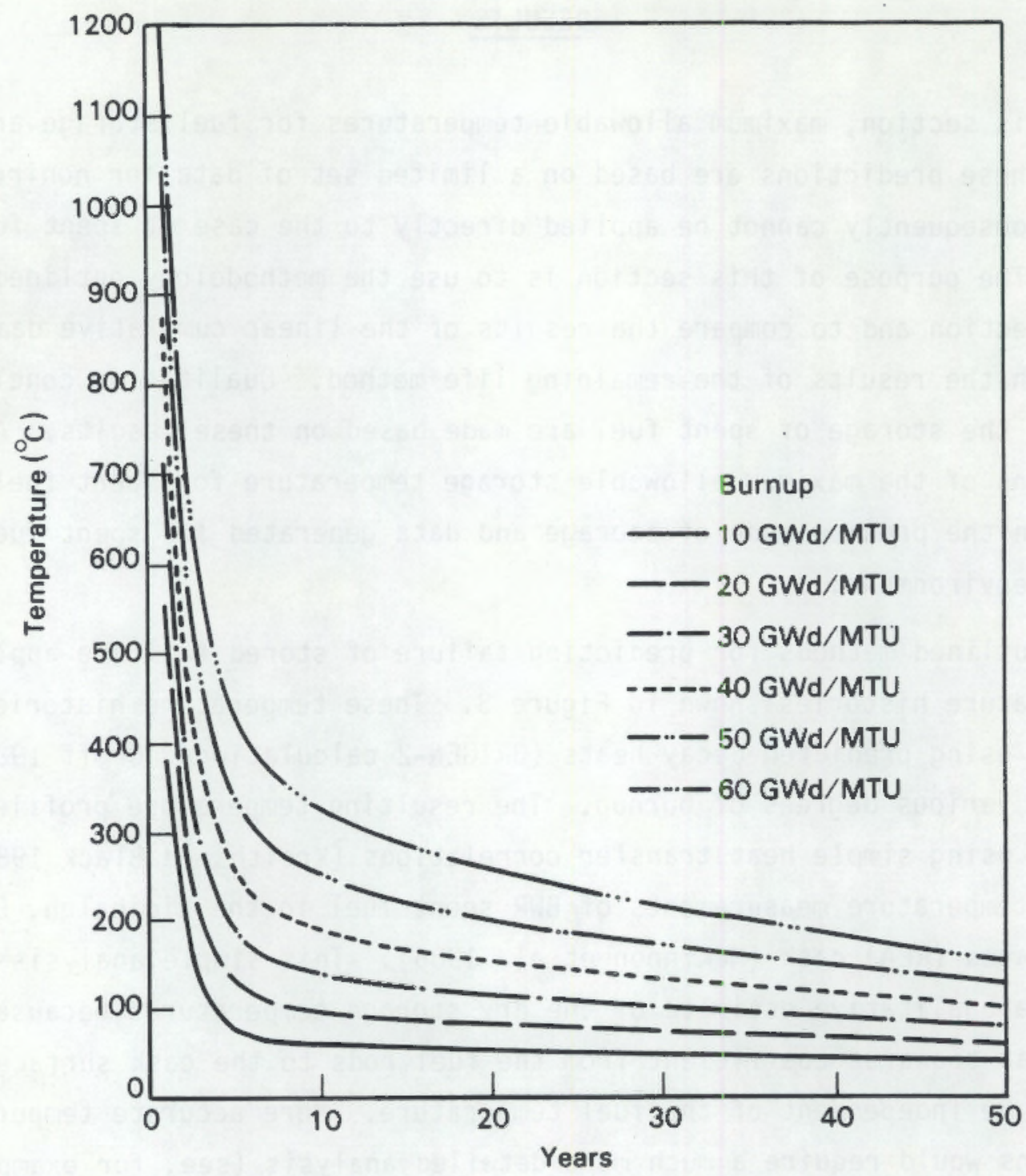

FIGURE 3. Estimates of Temperature History for BWR Spent Fuel in the REA Cask

expected, the remaining life method predicts higher allowable temperatures than does the linear cumulative damage method when the initial temperatures are above the point at which linear cumulative damage is assumed to become operable $\left(200^{\circ} \mathrm{C}\right)$. When the initial temperatures are below this point, both methods predict the same maximum temperature.

The calculated maximum temperatures show a strong dependence on the temperature-time profile. For a low-burnup fuel with a very rapid initial 
TABLE 3. Maximum Allowable Temperatures for Dry Storage Calculated Using Data for Nonirradiated $\mathrm{NO}_{2}$

\begin{tabular}{|c|c|c|c|c|}
\hline \multirow[b]{2}{*}{$\begin{array}{c}\text { Fuel } \\
\text { Burnup }\end{array}$} & \multicolumn{2}{|c|}{ Remaining Life Method } & \multicolumn{2}{|c|}{$\begin{array}{c}\text { Linear Cumulative } \\
\text { Damage Method }\end{array}$} \\
\hline & $\begin{array}{l}\text { Max. Temp. } \\
\left({ }^{\circ} \mathrm{C}\right) \\
\end{array}$ & $\begin{array}{l}\text { Req. Coo] ing } \\
\left.\left(Y_{r}\right)^{(a}\right)^{\text {ing }} \\
\end{array}$ & $\begin{array}{c}\text { Max. Temp. } \\
\left({ }^{\circ} \mathrm{C}\right) \\
\end{array}$ & $\begin{array}{l}\text { Req. Cooling } \\
\left.\left(Y_{r}\right)^{(a)}\right)^{i n g}\end{array}$ \\
\hline $10 \mathrm{GWd} / \mathrm{MTU}$ & 215 & 1.75 & 187 & 2.0 \\
\hline $20 \mathrm{GWd} / \mathrm{MTU}$ & 192 & 3.25 & 192 & 3.25 \\
\hline $30 \mathrm{GWd} / \mathrm{MTU}$ & 178 & 5.5 & 178 & 5.5 \\
\hline $40 \mathrm{GWd} / \mathrm{MTU}$ & 155 & 18.75 & 155 & 18.75 \\
\hline $50 \mathrm{GWd} / \mathrm{MTU}$ & 148 & 41,25 & 148 & 41.25 \\
\hline 60 GWd/MTU & (b) & $($ b) & (b) & \\
\hline
\end{tabular}

(a) Required cooling time refers to number of years needed before fuel will cool to calculated maximum temperature and air can be allowed access to fuel.

(b) Powder formation is predicted to occur even after a cooling period of 45 years.

decrease in temperature, the allowable temperature is considerably higher than for more slowly decreasing temperatures (assuming the same time to powder formation in both cases). However, because fuels with a higher burnup have longer times to powder (Gilbert et al. 1986), the results generated by increasing the time to powder formation by a factor of 20 (Table 4 ) may be more appropriate

TABLE 4. Maximum Allowable Temperatures for Dry Storage Calculated Assuming $t_{R}$ is Increased By a Factor of 20

\begin{tabular}{|c|c|c|c|c|}
\hline \multirow[b]{2}{*}{$\begin{array}{c}\text { Fuel } \\
\text { Burnup }\end{array}$} & \multicolumn{2}{|c|}{ Remaining Life Method } & \multicolumn{2}{|c|}{ Damage Method } \\
\hline & $\begin{array}{c}\text { Max. Temp. } \\
\left({ }^{\circ} \mathrm{C}\right)\end{array}$ & $\begin{array}{l}\text { Req. } \\
\left(Y_{r}\right)\end{array}$ & $\begin{array}{c}\text { Max. Temp. } \\
\left({ }^{\circ} \mathrm{C}\right) \\
\end{array}$ & $\begin{array}{l}\left.\operatorname{Req}_{\left(Y_{r}\right)}{ }^{C}(\mathrm{a})\right)^{i n g} \\
\end{array}$ \\
\hline $10 \mathrm{GWd} / \mathrm{MTU}$ & 253 & 1.5 & 253 & 1.5 \\
\hline $20 \mathrm{GWd} / \mathrm{MTU}$ & 266 & 2.25 & 242 & 2.5 \\
\hline $30 \mathrm{GWd} / \mathrm{MTU}$ & 254 & & 240 & 3.75 \\
\hline $40 \mathrm{GWd} / \mathrm{MTU}$ & 220 & 6.75 & 218 & 7.0 \\
\hline $50 \mathrm{GWd} / \mathrm{MTU}$ & 205 & 17.25 & 205 & 17.25 \\
\hline $60 \mathrm{GWd} / \mathrm{MTU}$ & 197 & 32.25 & 197 & 32.25 \\
\hline
\end{tabular}

(a) Required cooling time refers to number of years needed before fuel will cool to calculated maximum temperature and air can be allowed access to fuel. 
for higher-burnup fuels. The competing effects of temperature profile and time to powder formation will probably serve to balance the difference between highburnup fuels and low-burnup fuels to some degree.

Two input variables that may affect the calculated results are the assumed temperature of convergence for the remaining life curves and the required lifetime for storage in air. The effect of changes in these parameters on the maximum allowable storage temperatures is shown in Table 5. Shortening the required life of the spent fuel to 20 years shows little or no effect on the maximum allowable temperatures because most of the damage occurs at the initial higher temperatures, and time spent at the lower temperatures contributes insignificantly to the accumulated damage. Lowering the temperature at which the remaining life curves converge results in maximum temperatures that approach those calculated by the linear cumulative damage method. This result is expected because in this case the remaining life curves more closely parallel the reference remaining life curve.

The results indicate that the two primary factors associated with predicting maximum allowable storage temperatures are the temperature history of the storage and the time to powder formation of the fuel. The temperature history is a function of the actual storage configuration, the burnup of the fuel, and the age of the fuel at the time of emplacement. These variables are specific to the storage system and should be considered case-by-case. The time to powder formation is an undetermined function of the fuel type, burnup, microstructure, and surrounding environment. Such variables are unlikely to be completely quantified, so time to powder formation should be estimated conservatively based on present data and new data when available.

Verification of the outlined methods for predicting fuel integrity will require much more data than are presently available. The limited data suggest that the linear cumulative damage method, although possibly not the most accurate approach for determining the time to failure, is nonetheless conservative for decreasing-temperature histories. This method can be used with some confidence as the predictions include a measure of conservatism. As more 
TABLE 5. Effect of Changing Some of the Input Parameters in the Remaining Life Method

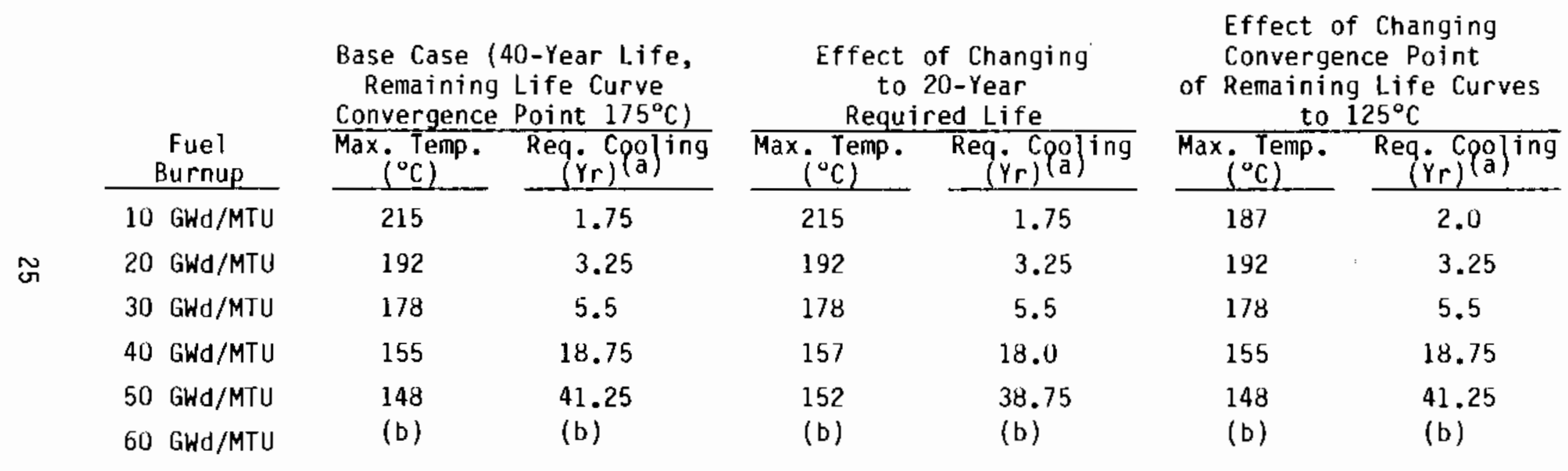

(a) Required cooling time refers to number of years needed before fuel will cool to calculated maximum temperature and air can be allowed access to fuel.

(b) Powder formation is predicted to occur even after a cooling period of 45 years. 
nonconstant temperature data become available, the remaining life approach can be validated and predictions based on this method may be used to decrease the amount of conservatisin.

Specific test programs are needed to validate these or any other methods for predicting fuel integrity and maximum storage temperatures. The remaining life method requires two major types of tests. The first tests should be step temperature change tests to describe the nature of the remaining life curves. Once these curves have been obtained (which would determine the applicability of the linear cumulative damage method or the remaining 15 fe methods), ramped temperature change tests should be performed to validate the method used to predict failure. Such tests will build confidence in the extrapolative use of cumulative damage approaches. 


\section{REFERENCES}

Anderson, J. S., L. E. J. Roberts, and E. A. Harper. 1954. "The 0xides of Uranium. Part VII. The Oxidation of Uranium." J. Chem. Soc. 3:3946-3959.

Aronson, S., R. B. Roof, and J. Belle. 1957. "Kinetic Study of the 0xidation of Uranium Dioxide." J. Chem. Phy. 27:(1):137-144.

Bailey, W. J., A. B. Johnson, D. E. Blahnik, R. J. Guenther, and D. D. Lanning. 1984. Surveillance of LWR Spent Fuel in Wet Storage. EPRI NP-3765, prepared for Electric Power Research Institute by Battelle, Pacific Northwest Laboratories, Richland, Washington.

Blackburn, L. D., D. G. Farwick, F. R. Fields, L. A. James, and R. A. Moen. 1978. Maximum Allowable Temperature for Storage of Spent Nuclear Fuel. HEDL-TME 7837, Hanford Engineering Development Laboratory, Richland, Washington.

Boase, D. G., and T. T. Vandergraff. 1977. "The Canadian Spent Fuel Storage Canister: Some Material Aspects." Nuclear Technology 32:60-71.

Bogdanoff, J. L., and F. Kozin. 1985. Probabilistic Models of Cumulative Damage. John Wiley \& Sons, New York.

Creer, J. M. 1984. "Decay Heat and Heat Transfer Predictions for Spent Fuel Storage Systems." In Proceedings, Second International Irradiated Fuel Storage Operating Experience and Development Program Workshop, pp. 157-209, Ontario Hydro., Toronto, Ontario, Canada.

Croff, A. G. 1980. A User's Manual for the ORIGEN-2 Computer Code. ORNL/TM7175, 0ak Ridge National Laboratory, Oak Ridge, Tennessee.

Cuta, J. M., D. R. Rector, and J. M. Creer. 1984. Thermal-Hydraulic Analysis of Consolidated Spent PWR Fuel Rods. EPRI NP-3764, prepared for ETectric Power Research Institute by Battelle, Pacific Northwest Laboratories, Richland, Washington.

Einziger, R. E., and R. V. Strain. 1984. "Effect of Cladding Defect Size on the Oxidation of Irradiated Spent LWR Fuel Below $360^{\circ} \mathrm{C}$." In Proceedings of Irradiated Fuel Storage: Operating Experience and Development Programs, October 17-18, 1984, pp. 599-625, Toronto, Ontario, Canada.

Einziger, R. E., and R. V. Strain. 1986. Oxidation of Spent Fuel Between $250^{\circ} \mathrm{C}$ and $360^{\circ} \mathrm{C}$. EPRI NP -4524 , prepared for Electric Power Research Institute hy Hanford Engineering Development Laboratory, Richland, Washington. 
Einziger, R. E., and R. E. Woodley. 1985. "Low Temperature Spent Fuel 0xidation Under Tuff Repository Conditions." In Proceedings of the Symposium on Waste Management, March 24-28, 1985, Tucson, Arizona (also HEDL-SA-3271FP).

Gilbert, E. R., N. J. Wildung, G. D. White, R. J. Guenther. 1983. "Methodology for Computing Limiting Temperature to Control $\mathrm{UO}_{2}$ Oxidation." In Transaction of the American Nuclear Society. October 30-November 3, 1983, Vo1. 45, pp. 86-87, San Francisco, California.

Gilbert, E. R., G. B. White, and C. A. Knox. 1984. "0xidation of U0, at $150^{\circ} \mathrm{C}$ to $350^{\circ} \mathrm{C} . "$ In Proceedings of Irradiated Fuel Storage: Operating Experience and Oevelopment Programs, October 17-18, 1984, pp. 551-598, Toronto, Ontario, Canada.

Gilbert, E. R., C. A. Knox, and G. D. White. 1985. Assessment of Nitrogen as an Atmosphere for Dry Storage of Spent LWR Fuel. PNL-5569, Pacific Northwest Laboratory, Richland, Washington.

Gilbert. E. R., C. A. Knox, and G. D. White. 1986. "Behavior of Spent Fuel in Nitrogen and in Air." In Proceedings of Third International Spent Fuel Storage Technology Symposium/workshop, April 8-10, 1986, pp. 5264-5278, Seattle, Washington.

Harrison, K. T., C. Padgett, and K. T. Scott. 1967. "The Kinetics of the Oxidation of Irradiated Uranium Dioxide Spheres in Dry Air." Journal of Nuclear Materials 23:121-138.

Hastings, I. J., D. McCracken, J. Novak, and K. Nash. 1983. "Postirradiation Behavior of U0, Fuel I: Elements at 220 to $250^{\circ} \mathrm{C}$ in Air." Nuclear Technology 63:254-265.

Hastings, 1. J., D. McCracken, J. Novak, and K. Nash. 1984. "Behavior in Air at $175-400^{\circ} \mathrm{C}$ of Irradiated $\mathrm{UO}_{2}$ Fuel." In Proceedings of Irradiated Fuel Storage: Operating Experience and Development Programs, October 17-18, 1984, pp. 626-654, Toronto, Ontario, Canada.

Hwang, W., and K. S. Han. 1986. "Cumulative Damage Models and Multi-Stress Fatigue Life Prediction". Journal of Composite Materials 20:125-153.

Johnson, A. B., Jr., and E. R. Gilbert. 1983a. Technical Basis for Storage of Zircaloy-Clad Spent Fuel in Inert Gas. PNL -4835 , Pacific Northwest Laboratory, Richland, Washington.

Johnson, A. B., Jr. and E. R. Gilbert. 1983b. "Reaction of Fuel Cladding with Cover Gases Under Dry Storage Conditions". In Proceedings of Spent Fuel/ Cladding Reaction During Dry Storage, August 17-18, 1983, pp. I1-I10, NUREG/CP-0049, sponsored by the U.S. Nuclear Regulatory Commission, Gaithersburg, Maryland. 
Johnson, W. A., and R. F. Meh1. 1939. "Reaction Kinetics in Processes of Nucleation and Growth." Transactions of the American Institute of Mining and Metallurgical Engineers 135:416-442.

Kreith, F., and W. Z. Black. 1980. Basic Heat Transfer. Harper and Row, New York.

McCaidin, J. 0., and G. Somorjai, eds. 1975. Progress in Solid State Chemistry. Vol. 9, Pergamon Press, New York.

Mckinnon, M. A., J. W. Doman, J. E. Tanner, R. J. Guenther, J. M. Creer, and C. E. King. 1986. BWR Spent Fuel Cask Performance Test. Vol. 1, PNL-5777, Pacific Northwest.Laboratory, Richland, Washington.

Moore, W. J. 1962. Physical Chemistry. Third Edition, Prentice-Hall, Inc., Englewood Cliffs, New Jersey, pp. 266-267.

Naito, K., and N. Kamegashira. 1976. "High Temperature Chemistry of Ceramic Nuclear Fuels with Emphasis on Nonstoichiometry". In Advances in Nuclear Science and Technology, eds., E. J. Henley and J. Lewiñs, Vol. 9, Academic Press, New York.

Novak, J., and I. J. Hastings. 1983. "Post-Irradiation Behavior of Defected $\mathrm{UO}_{2}$ Fuel Elements in Air at $220-250^{\circ} \mathrm{C}$." In Proceedings of Spent Fuel/ Cladding Reaction During Dry Storage, August 17-18, 1983, pp. A1-A8, NUREG/CP-0049, sponsored by the U.S. Nuclear Regulatory Commission, Gaithersburg, Maryland.

01 sen, C. S. 1984. Particulate and Gas Release from Light-Water-Reactor (LWR) Fuel Rods Stored in Inert and Dry Air. NUREG/CR-4056, EGG-2359. Prepared for the U.S. Nuclear Regulatory Commission by EG\&G Idaho, Idaho Falls, Idaho.

01 sen, C. S. 1985a. The Performance of Defected Spent LWR Fuel Rods in Inert Gas and Dry Air Storage Atmospheres. NUREG/CR-4074, EGG-2364. Prepared for the U.S. NucTear Regulatory Commission by EC\&G Idaho, Idaho Falls, Idaho.

01 sen, C. S. 1985b. Investigation of the Stability of LWR Spent Fuel Rods Bel ow $250^{\circ} \mathrm{C}$. NUREG/CR-4345, EGG-2409. Prepared for the U.S. Nuclear Regulatory Commission by EC\&G Idaho, Idaho Falls, Idaho.

Peehs, M., and J. Fleisch. 1986. "LWR Spent Fuel Storage Behavior." Journal of Nuclear Materials 137:190-202.

Rector, D. R., J. M. Cuta, and J. M. Creer. 1986. "Cask Consolidation Spent Fuel Thermal Analyses Using the COBRA-SFS Code." In Proceedings, Third International Spent Fuel Storage Technology Symposium/Workshop, Vol. 1, pp. S378-S379, Seattle, Washington. 
Roberts, L. E. J. 1954. "The 0xides of Uranium, Part V. The Chemisorption of oxygen on $\mathrm{UO}_{2}$ and on $\mathrm{UO}_{2}-\mathrm{ThO}_{2}$ " 3. Chem. Soc. $3: 3332$.

Simpson, K. A., and P. Wood. 1984. "Uranium Dioxide Fuel Oxidation in Air Below $350^{\circ} \mathrm{C}$ ". In Proceedings of Spent Fuel/Cladding Reaction During Dry Storage, August 17-18, 1983, pp. 70-86, NUREG/CP-0049, sponsored by the U.S. Nuclear Regulatory Commission, Gaithersburg, Maryland.

Thomas, L. E., J. M. McCarthy, and E. R. Gilbert. 1986. "TEM Examination of Oxidized LWR Spent Fuel." Presented at the Third International Spent Fuel Storage Technology Symposium/Workshop, April 8-10, 1986, Seattle, Washington.

Wadsten, T. 1977. "The Oxidation of Polycrystalline Uranium Dioxide in Air at. Room Temperature." J. Nuc1. Materials 64:315.

Wasywich, K. M., J. D. Chen, C. R. Frost, and J. Freire-Canosa. 1984. "LongTerm Behavior of Irradiated CANDU Fuel in Concrete Canister Storage - Test Results." In Proceedings, Second International Irradiated Fuel Storage Operating Experience and Development Program Workshop, pp. 393-431, Ontario Hydro., Toronto, Ontario, Canada.

Wheeler, D. 1983. "The Effect of Known Clad and Pellet Reactions on the GEC ESL Design of Dry Vault Store." In Proceedings of Spent Fuel/Cladding Reaction During Dry Storage, August $17-18,1983, \mathrm{pp} . \mathrm{HL}-\mathrm{H} 35$, NUREG/CR-0D49, sponsored by the U.S. Nuclear Regulatory Commission, Gaithersburg, Maryland.

Wheeler, C. L., R. A. McCann, N. J. Lombardo, D. R. Rector, and T. E. Michener. 1986. "HYDRA and COBRA-SFS Temperature Calculations for CASTOR-1C, REA2023, CASTOR-V/21, and TN-24P Casks." In Proceedings, Third International Spent Fuel Storage Technology Symposium/Workshop, Vol. 1, pp. S77-S98, Seattle, Washington.

White, D. G., E. R. Gilbert, and A. B. Johnson, Jr. 1983. "Oxidation of U02 at 150 to $350^{\circ} \mathrm{C} . "$ In Proceedings of Spent Fuel/Cladding Reaction During bry Storage, August $17-18,1983$, Pp. F1-F25, NUREG/CP-0049, sponsored by the U.S. Nuclear Regulatory Commission, Gaithersburg, Maryland.

Wood, P., M. J. Bennett, M. R. Houlton, and J. B. Price. 1985. "Oxidation and Fission Gas Release Behavior of Irradiated Uranium Dioxide in Air Below $400^{\circ} \mathrm{C}$." Nuclear Fuel Performance 2:116, Proceedings of BNES Conference, Stratford, U.K., March 25-29, 1985.

Woodford, D. A. 1979. "Creep Damage and the Remaining Life Concept." Journal of Engineering Materials and Technology 101:311-316. 
APPENDIX

DEVELOPMENT OF METHODS FOR DESCRIBING CUMULATIVE DAMAGE 
APPENDIX

DEVELOPMENT OF METHODS FOR DESCR IBING CUMULATIVE DAMAGE

Predicting spent fuel failure during storage, as a result of oxidation, requires a method by which short-term, constant temperature data and limited nonconstant temperature data $c$ an be extrapolated to long times with nonconstant temperatures. Ideally, oxidation kinetics should be used to define both the amount of damage accumulated and the time at which failure occurs. Because the oxidation kinetics have not been adequately quantified, operational definitions of damage accumulation are necessary. This appendix discusses two possible methods for predicting fuel failure due to oxidation. Failure is defined as time to powder formation.

The first method is the linear cumulative damage method (the PaimgrenMiner rule), which has been used previously to predict maximum allowable temperatures for fuel storage in oxidizing atmospheres (White, Gilbert, and Johnson 1983; Gilbert et al. 1983; Wheeler 1983; Einziger 1986). The second method, termed remaining life, is based on the work of Woodford (1979). The two methods are compared, and the linear cumulative damage method is shown to be a special case of the remaining life method.

\section{LINEAR CUMULATIVE DAMAGE METHOD (PALMGREN-MINER RULE)}

The first step in developing the linear cumulative damage method is to define the time to failure of an initially unoxidized specimen as a function of temperature for constant temperature tests. The time for powder formation $\left(t_{R}\right.$, the subscript $R$ denoting the reference time remaining) during a constant temperature test is assumed to be an Arrhenius function of temperature:

$$
t_{R}=A \exp (Q / R T)
$$

where $A$ and $Q$ are coefficients, $R$ is the gas constant, and $T$ is absolute temperature. The above equation appears to be a valid representation of the oxidation process at temperatures for which data are available, although data 
suggest that the activation energy, $Q$, may change at temperatures above approximately $300^{\circ} \mathrm{C}$ (Boase and Vandergraff 1977). At the temperatures of interest $\left(<300^{\circ} \mathrm{C}\right)$, it is assumed that $Q$ is constart.

The linear cumulative damage method (the Palmigren-Miner rule) is based on the assumption that the increment of damage accumulated during a time interval $t$ at temperature $T$ is directly proportional to the ratio of the time interval to the reference remaining iife, $t_{R}$, at that temperature. The damage increments are summed to determine the total damage (D) as shown below.

$$
\sum_{i} \frac{\Delta t_{i}}{t_{R}\left(\bar{T}_{i}\right)}=D
$$

Failure occurs when $D$ is equal to 1 . The above can be put in the more usual integral form by taking the limit as $\Delta t$ approaches zero:

$$
\int_{0}^{t} \frac{d \tau}{t_{R}(T(\tau))}=0
$$

Implicit in this formulation is the idea that damage accumulated during any time interval is independent of any previously accumulated damage. The remaining life $\left(t_{r}\right)$ at any temperature after some damage has been incurred can be found from:

$$
t_{r}=(1-0) t_{R}
$$

\section{REMAINING LIFE METHOD}

The remaininy life method is based on the work of Woodford (1979). The development of this method is conceptually different in that it considers the calculation of the remaining life, whereas the linear cumulative damage nethod calculates the amount of life used up.

The remaining life method is developed with reference to remaining life plots. A schematic of such a plot is shown in Figure A.l, where the scales 


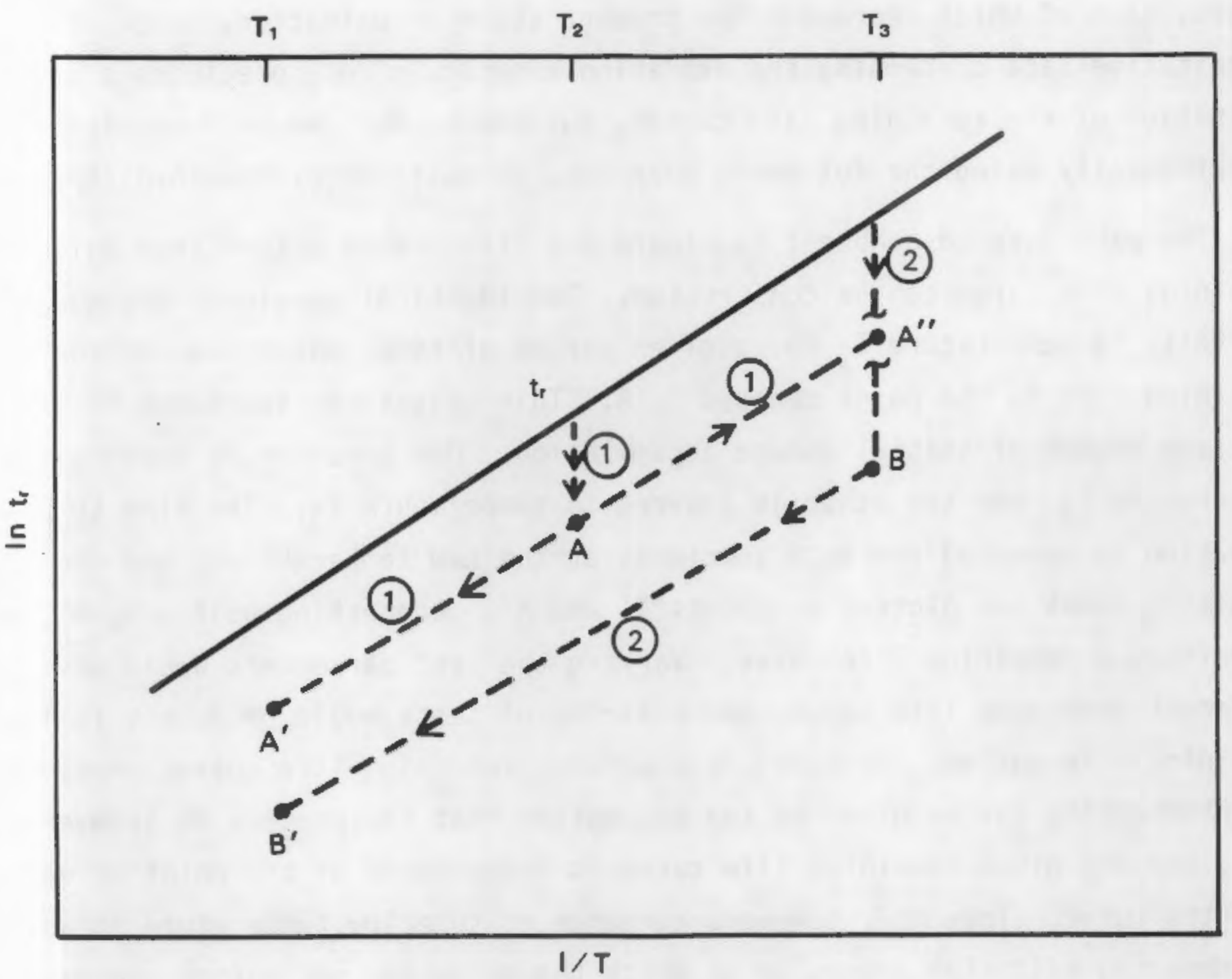

FIGURE A.1. Illustration of the Method for Obtaining Remaining Life Curves

were chosen to indicate an Arrhenius temperature dependence. The curve denoted $t_{R}$ is the reference remaining life (under constant temperature conditions) of an initially nonoxidized specimen as a function of temperature. The dashed curves represent partially oxidized states of the material and are termed constant damage curves by Woodford (1979). The term "damage" when used in the context of "constant damage curves" is not necessarily equivalent to the damage, D, defined in Equations $A .2$ and A.3. In order to eliminate confusion, the dashed curves will be termed "remaining life curves" even though "constant damage" is a physically more accurate term.

A remaining life curve is defined by a particular state of the material that is a function of the degree to which the material has oxidized. The progressive oxidation of the fuel defines a continuous family of remaining life 
curves, each of which represent the present state of oxidation. Lack of quantitative data concerning the oxidation kinetics of $\mathrm{UO}_{2}$ precludes a physical definition of the remaining life curves, but the curves can be determined experimentally using the following approach, as outlined by Woodford (1979).

The path labeled number 1 in Figure A.I illustrates a test from which a remaining life curve can be constructed. Two identical specimens are subjected initially to temperature $T_{2}$ for a given period of time, which reduces the remaining life to the point denoted by $A$. This causes the specimens to have the same amount of initial damage accumulation. One specimen is then raised to temperature $T_{1}$, and the other is lowered to temperature $T_{3}$. The time to powder formation is measured for both specimens at the new temperatures, and the resulting times are plotted as points $A^{\prime}$ and $A^{\prime \prime}$. Connecting points $A, A^{\prime}$, and A" defines a remaining life curve. Varying the test parameters would give a different remaining life curve, and a series of tests would produce a family of remaining life curves. As noted by Woodford, remaining life curves should be nonintersecting (as required by the assumption that the process is irreversible), and any given remaining life curve is independent of the point of entry onto the curve. They may, however, converge at some low temperature at which the damaging oxidation ceases or at which the oxidation mechanisms change.

The single specimen, single step temperature change tests performed with nonirradiated $\mathrm{UO}_{2}$ at $\mathrm{PNL}$ did not follow the above test method. Remaining life curves may still be determined from the data as shown by the path labeled number 2 in Figure A.1. In this case, a specimen was subjected to an initial temperature of $T_{3}$ for a given time period reducing its remaining life to the value denoted by point $B$. The temperature was then raised to $T_{1}$, and the time to powder formation was measured to determine point $B^{\prime}$. The remaining life curve is drawn by connecting points B and B'. A temperature decrease test results in a similar construction of a remaining life curve. This approach does not lead to verification of the shape of the remaining life curve, but it is assumed that the remaining life curve of a partially oxidized specimen also has an Arrhenius temperature dependence.

The remaining life method can be developed in terms of the remaining life curves. As a first step, the remaining life $\left(t_{r}\right)$ is considered as the 
dependent variable, while time $(t)$ and temperature $(T)$ are taken as independent variables. The total differential of $t_{r}$ is given by the following equation:

$$
d t_{r}=\frac{\partial t r}{\partial t} d t+\frac{\partial t r}{\partial T} d T
$$

The term $\partial t_{r} / \partial t$ represents the change in remaining life with respect to time at constant temperature. Because the remaining life will decrease in direct proportion to the amount of time elapsed (at constant temperature), this term is equal to -1 . The other partial derivative, $\partial t_{r} / \partial T$, represents the slope of a remaining life curve at the point in question. This leads to the following differential equation for remaining life:

$$
\frac{d t_{r}}{d t}=-1+\frac{\partial t_{r}}{\partial T} \frac{d T}{d t}
$$

subject to the initial conditions that $t_{r}=t_{R}\left(T_{0}\right)$, where $T_{0}$ is the initial temperature.

Equation A.6 is an operational equation independent of the actual process of damage accumulation (i.e., the equation is valid for both linear and nonlinear damage accumulation). Variable temperature histories are described by the term dT/dt. The term $\partial t_{r} / \partial T$ incorporates the characteristics of the remaining life curves that can be defined experimentally. To apply Equation A.6, step temperature change tests are needed to define the remaining life curves. The prediction of failure can then be validated by comparing the predictions of the model with the results of temperature ramp tests.

\section{COMPARISON OF THE TWO METHOOS FOR FAILURE PREDICTION}

The nature of the remaining life curves gives an indication of the applicability of a given failure prediction method to the process under consideration. The linear cumulative damage method should result in remaining life curves as shown in Figure A.2. All of the remaining life curves are parallel to the reference curve labeled $t_{R}$ as required by the Palmgren-Miner rule. As 


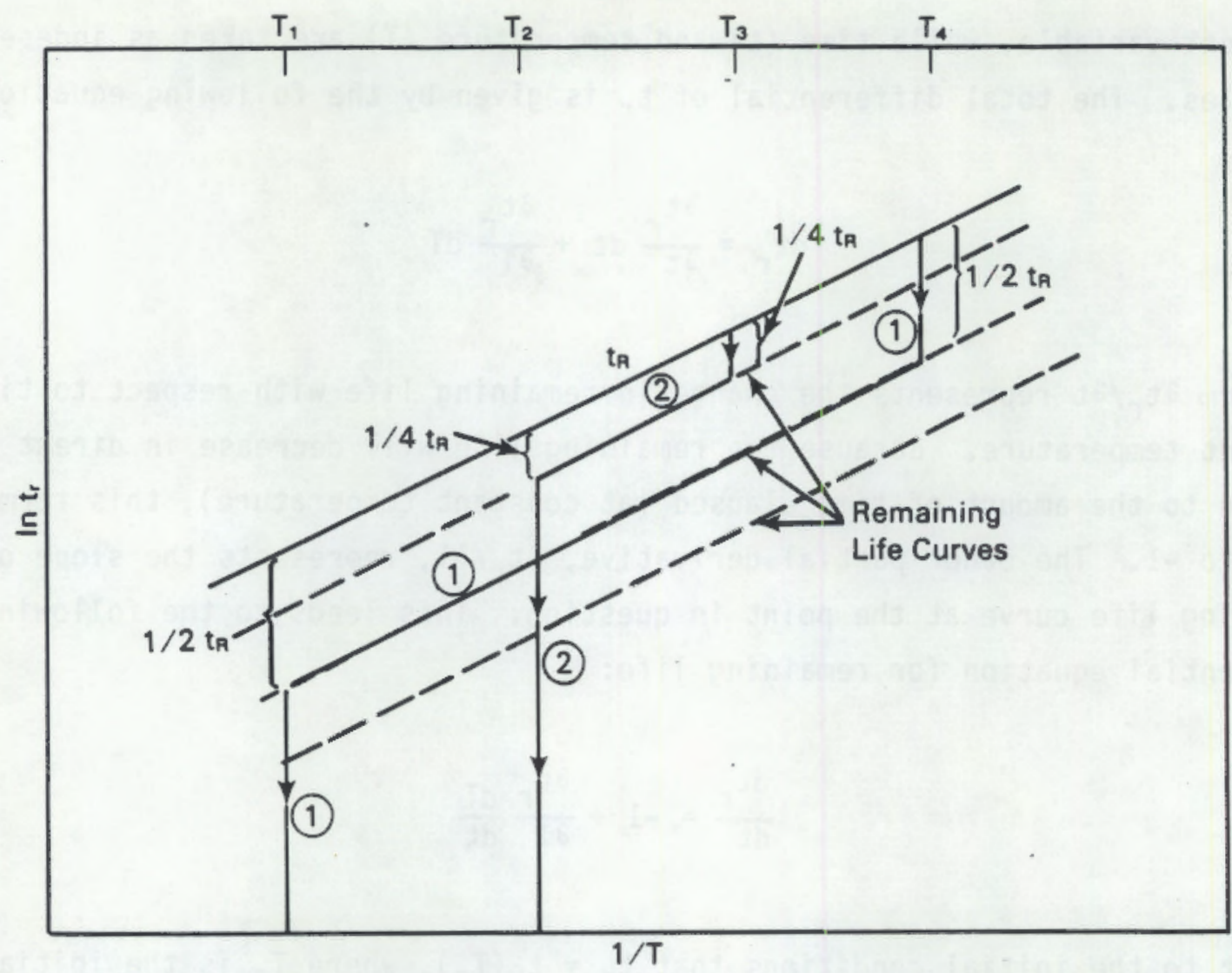

FIGURE A.2. Remaining Life Curves When Linear Cumulative Damage is Operable

an example, if $1 / 2$ of the life of the material were used up at some temperature $T_{4}(D=1 / 2)$. and the temperature was then changed to $T_{1}$, it would be expected that half of the reference $1 \mathrm{ife}$ at this new temperature would be available before powder formation would occur (path 1 in Figure A.2). Similarly, if $1 / 4$. of the life were used up at $T_{3}$, then at $T_{2}, 1 / 4$ of the life also would have been used up, leaving $3 / 4$ of the life remaining at $T_{2}$ (path 2, Figure A.2). This reasoning implies that the remaining life curves should be displaced by a constant amount from the reference constant temperature curve when plotted on a logarithmic scale as in Figure A.2. Such a displacement results in remaining life curves parallel to the reference remaining life curve.

Equation A.6 is not restricted to use when the remaining life curves are as described above and linear cumulative damage is operable. The remaining life method has broader applicability than the linear cumulative damage method in that it can address situations in which the remaining life curves are skewed 
with respect to the reference remaining life curve (as in the case suggested by the PNL step temperature change test data). The linear cumulative damage method is, however, a special case of the remaining life method as shown by the following analysis.

Consider the partial derivative term $\partial t_{r} / \partial T$ in Equation A.6. Because of the assumed Arrhenius temperature dependence of the remaining life curves, the following is seen to be true when linear cumulative damage is operable:

$$
\frac{\partial t_{r}}{\partial T}=\frac{t_{r}}{t_{R}} \cdot \frac{d t_{R}}{d T}
$$

Substituting into Equation A.6 results in:

$$
\frac{d t_{r}}{d t}=-1+\frac{t_{r}}{t_{R}} \frac{d t_{R}}{d t}
$$

Using the following identity:

$$
t_{R} \frac{d}{d t}\left(\frac{t_{r}}{t_{R}}\right)=\frac{d t_{r}}{d t}-\frac{t_{r}}{t_{R}} \frac{d t_{R}}{d t}
$$

Equation A.8 becomes:

$$
\frac{d}{d t}\left(\frac{t_{r}}{t_{R}}\right)=-1 \frac{1}{t_{R}}
$$

Integrating Equation $A .10$ and noting that $\left(\frac{t_{r}}{t_{R}}\right)_{t=0}=1$, this equation is seen to be identical to Equation $A .4$ because of the definition of damage, $D$, given by Equation A.3. This result shows that the linear cumulative damage method is a special case of the remaining life method. 


\section{REFERENCES}

Boase, D. G., and T. T. Vandergraff. 1977. "The Canadian Spent Fuel Storage Canister: Some Material Aspects." Nuclear Technology 32:60-71.

Gilbert, E. R., N. J. Wildung, G. D. White, R. J. Guenther. 1983. "Methodology for Computing Limiting Temperature to Control $\mathrm{UO}_{2}$ oxidation." In Transactions of the American Nuclear Society. October 30-November 3, 1983 , Vol. 45, pp. 86-87, San Francisco, California.

Wheeler, D. 1983. "The Effect of Known Clad and Pellet Reactions on the GEC ESL Design of Dry Vault Store". In Proceedings of Spent Fuel/Cladding Reaction During Dry Storage, August 17-18, 1983, Pp. Hi-H35, NUREG/CP-D049, sponsored by the U.S. Nuclear Regulatory Commission, Gaithersburg, Maryland.

White, D. G., E. R. Gilbert, and A. B. Johnson, Jr. 1983. "0xidation of $\mathrm{UO}_{2}$ at 150 to $350^{\circ} \mathrm{C} . "$ In Proceedings of Spent Fuel/Cladding Reaction During bry Storage, August 17-18, 1983, pp. F1-F25, NUREG/CP-D049, sponsored by the U.S. Nuclear Regulatory Commission, Gaithersburg, Maryland.

Woodford, D. A. 1979. "Creep Damage and the Remaining Life Concept." Journal of Engineering Materials and Technology 101:31:-316. 


\section{DISTRIBUTION}

No. of

Copies

OFFSITE

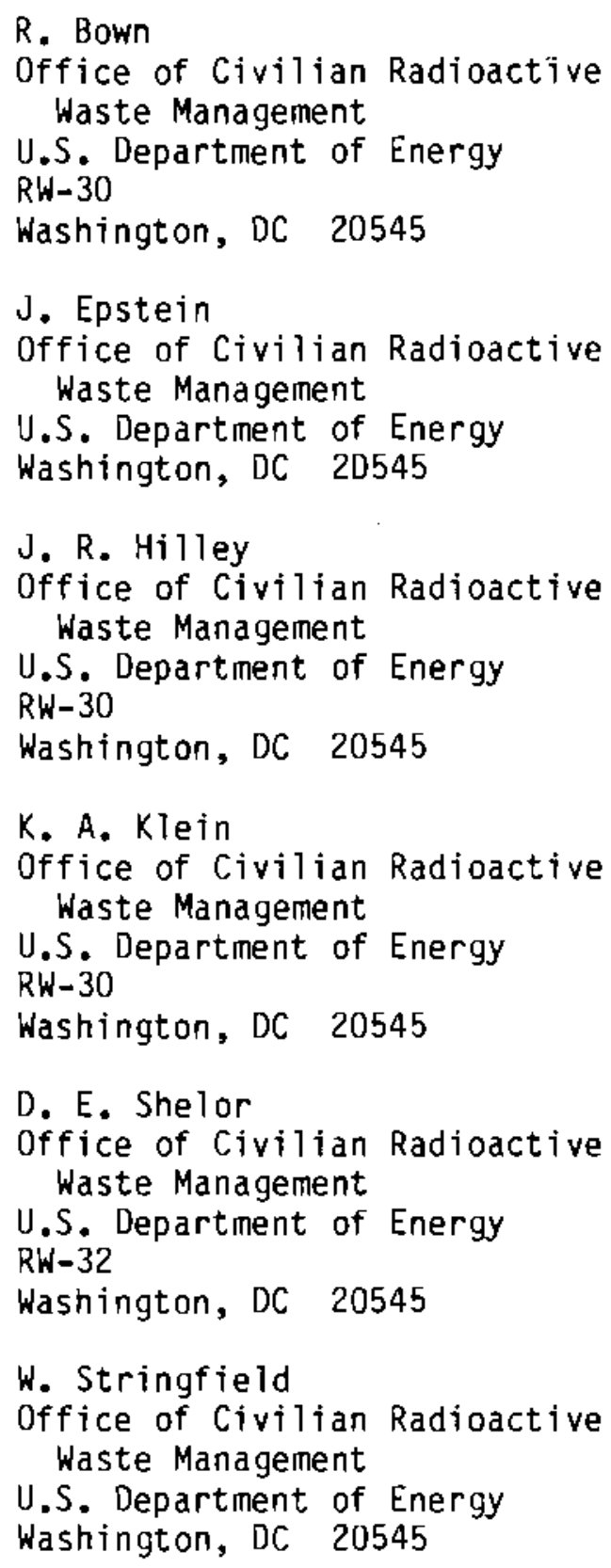

No. of

Copies

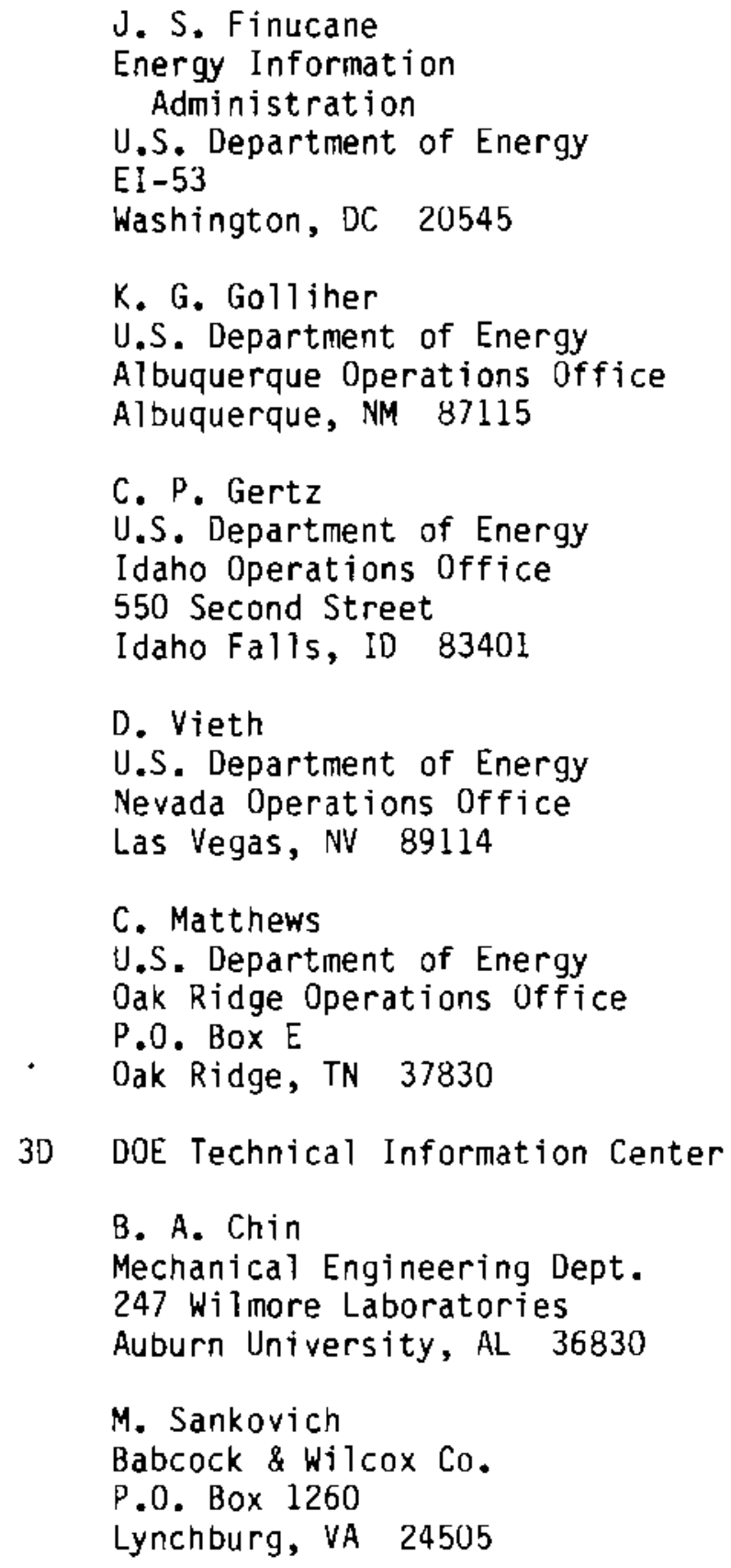

M. Sankovich

Lynchburg, VA 24505 
No, of

Copies

L. A. Walton

Babcock \& Wilcox Co.

P.0. Box 10935

Lynchburg, VA 24506

P. A. File

Baltimore Gas and Electric Co.

Calvert Cliffs Nuclear Power

Plant

Lusby, MO 20657

J. A. Carr

Battelle Project Management

Division

Office of Nuclear

Waste Isolation

$505 \mathrm{King}$ Avenue

Columbus, $\mathrm{OH} 43201$

B. A. Rawles

Battelle Memorial Institute

Office of Nuclear Waste

Isolation

$505 \mathrm{King}$ Avenue

Columbus, $\mathrm{OH} 43201$

R. Kohti

Battelle Columbus Division

$505 \mathrm{King}$ Avenue

Columbus, $\mathrm{OH} 43201$

V. Pasupathi

Battelle Columbus Oivision

$505 \mathrm{King}$ Avenue

Columbus, $\mathrm{OH} 43201$

T. W. Wood

Battelle Memorial Institute Washington Operations

2030 M Street-NW

Suite 800

Washington, DC 20036

G. A. Townes

BE Inc.

P.0. Box 145

New Ellenton, SC 29809
No. of

Copies

R. L. Hails

Bechtel Power Corporation

15740 Shady Grove Rd.

Gaithersburg, M0 20760

R. Kunita

Carolina Power \& Light Co.

P.0. Box 1551

Raleigh, NC 27602

G. C. Jobson

Chem-Nuclear Systems, Inc. One Greystone West Building

240 Stoneridge Drive, Suite 100

Columbia, SC 29210

N. Fuhrman

Combustion Engineering, Inc. 1000 Prospect Hill Road

windsor, CT 06095

R. L. Moscardini

Combustion Engineering, Inc.

1000 Prospect Hill Road

Windsor, CT 06095

G. P. Wagner

Commonwealth Edison

Nuclear Stations Division

P.0. Box 767

Chicago, IL 60690

T. J. Marz

Consumers Power Company

1945 W. Parnall Road

Jackson, MI 49201

S. 3. Raffety

Dariland Power Coop.

LaCrosse, WI 54601

R. W. Rasmussen

Duke Power Company

P.0. Box 33189

Charlotte, NC 28242 
No. of

Copies

R. Stanford

Edison Electric Institute

1111 19th St., NW

Washington, DC 20036

O. H. Schoonen

EG\&G Idaho, Inc.

P.0. Box 1625

Idaho Falls, ID 83415

R. F. Williams

Electric Power Research Institute

P.0. Box 10412

Palo Alto, CA 94303

R. W. Lambert

Electric Power Research Institute

P.0. Box 10412

Palo Alto, CA 94303

G. T. Zamry

Florida Power \& Light Co. $9250 \mathrm{~W}$. Flagler St.

Miami, FL 33174

B. J. Baxter

GA Technologies Inc.

P.0. Box 81608

San Diego, CA 92138

E. E. Voiland

General Electric Co.

Morris Operation

Morris, IL 60450

W. L. Dobson

Gilbert Associates, Inc.

P.0. Box 1498

Reading, PA 19603

V. J. Barnhart

GNS I

135 Darling Dr.

Avon, CT 06001
No. of

Copies

B. Handly

Houston Lighting \& Power Co.

Nuclear Fuels, Baybrook

P.0. Box 1700

Houston, TX 77001

J. A. McBride

E. R. Johnson Associates, Inc.

11702 Bowman Green Drive

Reston, VA 22090

L. M. Trosten

LeBoeuf, Lamb, Leiby, \& MacRae

1333 New Hampshire Ave. Nw

Washington, DC 20036

L. D. Ramspott

Lawrence Livermore National Laboratory

P.0. Box 808

Mail Stop L404

Li vermore, CA 94550

V. M. Oversby

Waste Package Task, NNWSI

Lawrence Livermore National Laboratory

P.0. Box 808

L.206

Livermore, CA 94550

J. H. Garrity

Maine Yankee Atomic Power Co. Edison Drive

August, ME 04336

G. D. Whittier

Maine Yankee Atomic Power Co.

Edison Drive

Augusta, ME 04336

R. Whale

Michigan Public Service Comtrission

6545 Mercantile Way

Lansing, MI 48909 
No. of

Copies

R. Calabro

Northeast Utilities Service Co. P.0. Box 270

Hartford, CT 06101

R. Isakson

Northeast Utilities Service Co. P.0. Box 270

Hartford, CT 06101

E. Krinick

Northeast Utilities Service Co. P.0. Box 270

Hartford, CT 06101

M. T. Pitek

Northeast Utilities Service Co. P.0. Box 270

Hartford, CT 06101

J. Houston

Nuclear Assurance Corp.

5720 Peachtree Parkway

Norcross, GA 30092

J. M. Viebrock

Nuclear Assurance Corp. 5720 Peachtree Parkway

Norcross, GA 30092

J. Clark

Nuclear Fuel Services

6000 Executive Blvd.

Rockville, MD 20852

R. T. Haelsig

Nuclear Packaging inc.

1010 S. 336th St.

Federal Way, WA 98003

G. J. Antonucci

NUS Corporation

910 Clopper Rd.

Gathersburg, MD 20878
No. of

Copies

J. V. Massey

NUTECH Engineers

145 Martinvale Lane

San Jose, CA 95119

J. Van Cleve

Oak Ridge National Laboratory

P.0. Box $X$

Oak Ridge, TN 37831

M. Litterman

Pacific Gas \& Electric, Trojan Fuel

121 S.W. Salmon St.

Portiand, OR 97204

M. L. Pickiesimer

Pic Products Co.

221 Meadowood Lane

Montevello, AL 35115

Portland General Electric

131 S.W. Salmon Street

Portland, OR 97204

G. C. Allen

Sandia National Laboratory

Transportation Technology Center

P.0. Box 5800

Albuquerque, NM 87185

J. F. Ney

Sandia National Laboratory

Transportation Technology Center

P.0. Box 5800

Albuquerque, NM 87185

E. Kuhns

Stone and Webster Engineering Corp.

1 Penn Plaza

250 W. 34th St.

New York, NY 10119

J. B. Moegling

Tennessee Valley Authority

4D4 Krystal Building

Chattanooga, TN 37401 
No. of

Copies

E. Gordon

Transnuclear, Inc.

507 Newmark Esplanade

Rockville, MD 20850

J. Mangusi

Transuclear, Inc.

1 N. Broadway

White Plains, NY 10601

B. R. Teer

Transnuclear, Inc.

1 N. Broadway

White Plain, NY 10601

C. E. King

Uranium Mgt. Corp.

310 DeGuigne Drive

Sunnyvale, CA 94086

N. H. Davison

U.S. Nuclear Regulatory Commission

Office of Nuclear Materials Safety and Safeguards

Washington, DC 20555

C. Feldman

U.S. Nuclear Regulatory Commission

Office of Nuclear Regulatory Research

Washington, DC 20555

3. Roberts

U.S. Nuclear Regulatory Commission

office of Nuclear Materials Safety and Safeguards

washington, DC 20555

L. C. Rouse

U.S. Nuclear Regulatory Commission

Spent Fuel Storage Installation

Division of Fuel Cycle and Material Safety

Washington, DC 20555
No. of

Copies

S. P. Turel

U.S. Nuclear Regulatory Commission

Office of Nuclear Regulatory

Research

Washington, DC 20555

W. J. Wachter

U.S. Tool and Die, Inc.

4030 Route 8

Allison Park, PA 15101

G. E. Lucas

University of California

Dept. of Chemical and Nuclear Engineering

Santa Barbara, CA 93106

D. R. 01 ander

University of California

647 San Fernando Ave.

Berkeley, CA 94707

S. P. Xeck

Virginia Electric \& Power

P. 0 . Box 26666

Richmond, VA 23261

M. L. Sinith

Virginia Electric \& Power

P.0. Box 26666

Richmond, VA 23261

J. A. Nevshemal

Westec Services, Inc.

P.0. Box 765

Muscatine, IA 52761-0765

E. S. 8assler

Westinghouse Electric Corp. Box 2728

Pittsburgh, PA 15230 
No. of

Copies

A. R. Hakl

Westinghouse Electric Corp.

Waste Technology Services Div.

P.0. Box 10864

Pittsburgh, PA 15236

N. Dayem

R. F. Weston Co. 2301 Research Blvd.

Rockville, MD 20850

E. Benz

R. F. West on Co. 2301 Research Blvd.

Rockville, MD 20850

ONSITE

4 DOE Richland Operations Office

J. P. Collins

R. D. Izatt

D. C. Langstaff

M. J. Plahuta

3 Hanford Engineering Development Laboratory

R. E. Einziger

R. L. Knecht

R. E. Woodley

Rockwell Hanford Company

C. L. Brown
No. of

Copies

69 Pacific Northwest Laboratory

M. J. Apted

W. U. Bailey

J. 0. Barner

G. H. Beeman (10)

J. L. Braitman

T. K. Campbell

B. M. Cole

T. T. Claudson

J. M. Creer

M. D. Freshley

S. R. Gano

E. R. Gilbert (20)

R. J. Guenther

C. M. Heeb

R. E. Heineman

A. B. Johnson, Jr.

C. A. Knox

D. K. Kreid

M. R. Kreiter

J. L. McEl roy

G. L. McVay

L. G. Morgan

D. F. Newman

C. R. Reid (5)

J.T.A. Roberts

K. J. Schneider

D. J. Silviera

L. A. Strope

R. C. Walling

G. D. White

Publishing Coordination (2)

Technical Library (5) 